Ultimate strengths of $\mathrm{FRC}$ rectangular columns subjected to simulated seismic loading: Experimental database and new models

Peer-reviewed author version

CAI, Gaochuang \& DEGEE, Herve (2016) Ultimate strengths of FRC rectangular columns subjected to simulated seismic loading: Experimental database and new models. In: Archives of Civil and Mechanical Engineering, 17(1), p. 96-120.

DOI: 10.1016/j.acme.2016.08.008

Handle: http://hdl.handle.net/1942/22584 


\title{
Ultimate strengths of FRC rectangular columns subjected to simulated seismic loading: Experimental database and new models
}

\section{Gaochuang Cai*, Hervé Degée,}

CERG, Faculty of Engineering Technology, Hasselt University, Diepenbeek, Belgium

\begin{abstract}
While there are many experimental investigations focusing on seismic behaviour of fibre reinforced concrete (FRC) columns, the studies regarding the accuracies and conservativeness of existing seismic strength models of FRC columns are limited. This paper presents a seismic research database of 322 FRC columns obtained from a comprehensive literature investigation. The characteristic of the database and the effects of main variables on the seismic strengths of FRC columns are analysed in detail, the accuracies of existing strength models of FRC column are also examined as well. In addition, using the database, considering the effects of fibre and other structural factors on FRC columns, Priestley et al. shear and CFB-FIP moment models are modified respectively. Results show that the two proposed strength models both present better evaluation than other models. On the other hand, a detailed method for assessing the potential failure mode of FRC column subjected to seismic loads is also suggested using the two strength models. The comparative results verify the feasibilities and accuracies of the assessment method in FRC columns.
\end{abstract}

Keywords: Fibre reinforced concrete; Shear strength; Flexure strength; Failure mode; Seismic assessment; 


\section{Nomenclatures}

\begin{tabular}{|c|c|c|}
\hline$\omega_{1}, \omega_{1 f}$ & - & Mechanical reinforcement ratio; \\
\hline$\rho_{L}$ & - & Longitudinal reinforcement ratio; \\
\hline$d$ & - & Overall depth of column, $\mathrm{mm}$; \\
\hline$d^{\prime}$ & - & Effective depth of column, $\mathrm{mm}$; \\
\hline$A_{s l}$ & - & Area of longitudinal steel, $\mathrm{mm}^{2}$; \\
\hline$P$ & - & Applied axial load, $k N$; \\
\hline$b$ & - & Width of columns; \\
\hline$f_{c}^{\prime}$ & - & Concrete compressive strength, $M P a$; \\
\hline$\rho_{F}$ & - & Fibre volume fraction, $\%$; \\
\hline$V_{f}$ & - & Shear contribution provided by fibre; \\
\hline$V_{s}$ & - & Shear component of transverse steel; \\
\hline$A_{g}$ & - & Gross area of cross section; \\
\hline$v_{b}$ & - & Basic shear stress in ASCE-ACI model; \\
\hline$f_{v c d}$ & - & Basic shear stress in JSCE model; \\
\hline$\rho_{T}$ & - & Area ratio of transverse steel; \\
\hline$a / d$ & - & Shear span ratio of columns; \\
\hline$k_{f}$ & - & Affecting factors in fibre strength; \\
\hline$j$ & - & Calculative lever depth, $\mathrm{mm}$; \\
\hline$c$ & - & Depth of compression zone, $\mathrm{mm}$ \\
\hline$a$ & - & Calculation height of columns; mm \\
\hline$\rho_{F p}$ & 一 & Polypropylene fibre ratio in concrete; \\
\hline$n$ & - & Axial load ratio of columns; \\
\hline$S / d$ & - & Normalized spacing of shear steel; \\
\hline$V_{\text {exp }}$ & - & Experimental shear strength, kN; \\
\hline$V_{\text {sh,cal }}$ & - & Calculated shear strength, kN; \\
\hline$V_{f l, c a l}$ & - & Calculated flexure strength, $\mathrm{kN}$; \\
\hline
\end{tabular}

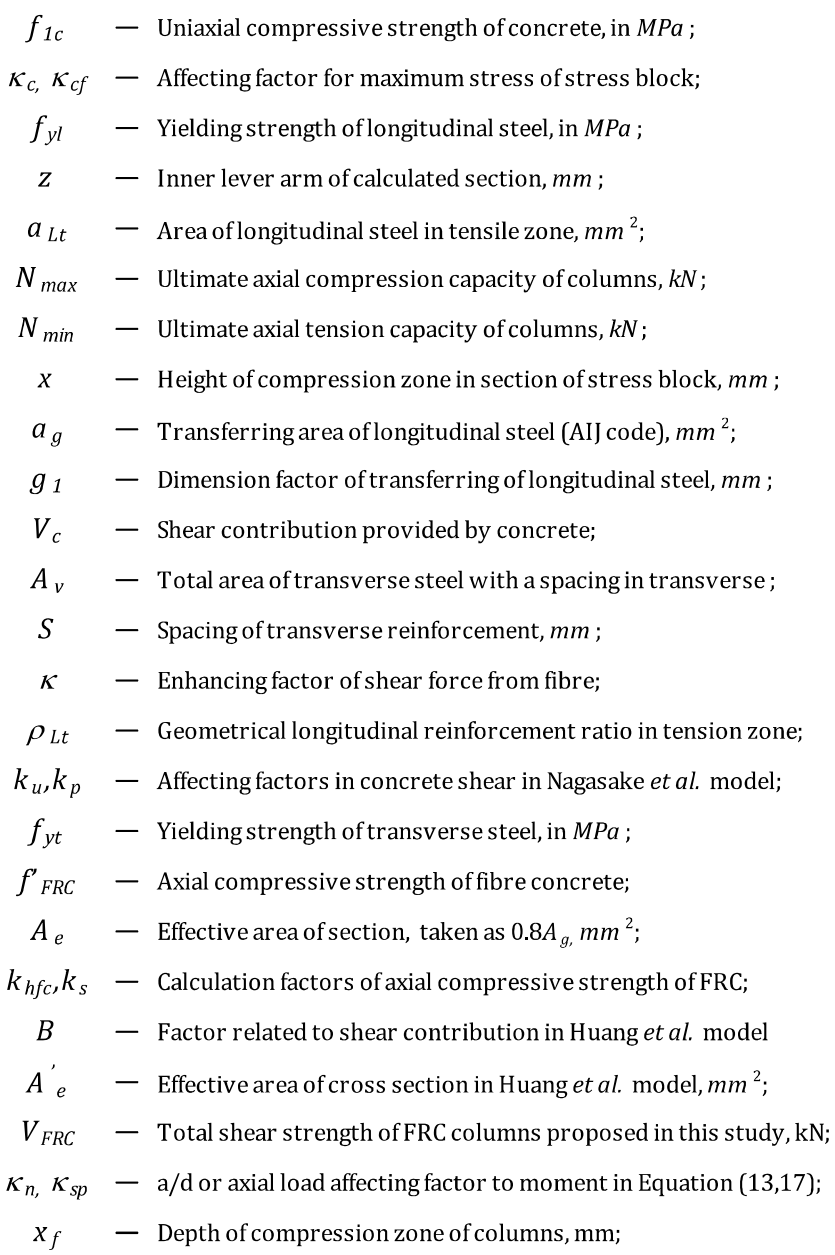




\section{Introduction}

The ultimate strength and potential failure mode of reinforced concrete $(R C)$ members are very important to the design of building structures, for their reasonable analyses and reliable predictions can guide how to prevent sudden and brittle shear failure. With these considerations, high performance concrete (HPC) is being concerned and applied increasingly by structural designers and builders. HPC elements have many benefits for structures majorly including high load capacity, small-cross section and good durability. Up to now, numerous endeavours have been carried out to improve the understandings of shear resisting and transferring mechanism of RC structural members using HPC subjected various loads. There are also many studies which tried to optimize the design method and damage assessment of HPC structural members. Among these HPCs, fibre reinforced concrete $(F R C)$ does is an important representatives and is being increasingly concerned. The addition of fibre in RC members not only can improve the cracking resistance capacity and flexure strength of members[1], delay the spalling of concrete cover $[2,3]$ and enhance their deformation capacity of members [2-8], but also can increase the shear strength of the elements to prevent effectively brittle shear failure.

Bischoff (9) reported that FRC has high tensile resistance capacity involving the initial cracking strength of RC members because they are able to carry tensile forces when they are opened cracks. This can prevent the further development of the cracks and can be transferred into the deformation resisting of members. Besides, the use of fiber can reduce the requirement of transverse reinforcement in FRC members, especially for their seismic design [13]. This is very significant to some important members which usually need a number of reinforcements such as beam-column joints. Therefore, the use of fibre can effectively solve the congestion of rebar in the joints to improve effectively their construction quality [10].

On the basic of the above descriptions, the positive effect of fiber should be considered in the evaluation of ultimate strength and of other properties of FRC members subjected to seismic loads such as ductility and failure and energy dissipation capacity etc. Most of current design codes such as ACI 318 [11] and Eurocode 8 [12], however, do not take into account the favorable

effect of fiber. Moreover, the current design previsions of FRC members are usually empirical and different between various countries in the world [13]. Up to now, there are not internationally accepted calculation models for predicting the ultimate strengths and reliable methods to assess the potential failure mode of FRC members as well. In addition, little thing was known about the accuracy and conservativeness of the existing ultimate strengths models and proposals. This implies that to build seismic research database and to develop a comprehensive method for predicting the failure models of FRC columns are indispensable and significant.

As most important support parts in building structure system in earthquake prone zone, and as a beginning of big seismic database, this paper firstly focuses on the studies of FRC columns. The main objectives of the study have two: (1) to build a seismic research database of FRC columns to study comprehensibly and comparatively the existing ultimate strength models of 
FRC columns; (2) to develop an acceptable judgment method to assess the potential failure modes of FRC columns subjected to seismic loads. It should be noted that this research majorly focuses on the behavior of FRC columns under simulated seismic loads, i.e. under combined axial and reversed lateral loading. The test data is usually obtained from laboratory investigation which uses small-scale specimen. In summary, this paper

a) Builds a comprehensive seismic research database of FRC columns via collecting the published test studies carried out by various countries;

b) Analyzes the influences of main structural parameters affecting the seismic strengths of FRC columns, including ultimate flexural and shear strengths;

c) Examines existing strength models of FRC columns and modifies them via reconsidering some main key structural factors;

d) Recommends a method to assess the potential failure modes of FRC columns under seismic loads;

\section{Previously proposed models for predicting the ultimate strength of FRC/RC columns}

In this section, some existing design models for predicting the ultimate capacities of FRC columns under seismic loads are reviewed shortly, including shear and flexural strength models. According to the practice manual in ACI code [14] or other research [23], the enhancing effect of fibre can be taken into account in the compressive strength of FRC. Therefore, some representative strength models developed on the basis of the test studies and analyses of normal concrete member also are presented and used in this study.

\subsection{Flexural strength models}

Regarding the calculation of flexure strength of RC columns, the mothed using ACI rectangular concrete stress block in compressive zone of calculation section is well known. Assuming a mean compressive stress of $0.85 \mathrm{f}_{\mathrm{c}}{ }^{\prime}$ in this block and the ultimate compressive strain of concrete of 0.003 , the theoretical flexural strength of RC columns can be calculated. Up to now, of course, some improved compressive stress blocks have been proposed such as NewRC model in Japan [15] and CEB-FIP MC90 method [16] in Europe. However, all of the methods usually need to conduct a complicated calculation of calculation section. Therefore, as a comparative flexural strength model, this study presents a simplified block calculation method proposed by CEB-FIP MC90. Besides, considering the difference between the resistance of RC beams and columns subjected to seismic loads, this paper just uses the strength models developed on the basis of the study of RC/FRC columns.

\section{CEB-FIP MC90 model [16]}

The ideal flexural strength of RC columns can be calculated by using a simplified stress block over the full depth of compressive zone obtained from CEB-FIP MC 90. This model ignored the normally low amount of compressive reinforcement and then suggested the height of concrete compression zone $(x)$ with uniform stress block can be given by, 


$$
\begin{aligned}
x & =\frac{\omega_{1}}{\kappa_{c}} d=\frac{\rho_{L} f_{y l} / f_{1 c}}{\left(1-f_{1 c} / 250\right)} d^{\prime} \\
f_{1 c} & =0.95 f_{c}^{\prime}
\end{aligned}
$$

Therefore, according to the moment equilibrium in the cross section of column, the flexural capacity (moment) of RC column is calculated as,

$$
M_{u}=A_{s l} f_{y l} Z=A_{s l} f_{y l}\left(1-0.5 x / d^{\prime}\right) d^{\prime}
$$

In this equation, $Z$ is inner lever arm. Because the used inner lever arm is lower than the one obtained based on a more realistic stress distribution, in theory, even for RC columns, the model should be conservative when it is used to predict the flexural strength of column.

\section{Architecture institute Japan (AIJ) models [17]}

In order to evaluate the seismic ultimate capacity of RC structures and determine their collapse failure mode, the guideline of ultimate strength and deformation capacity of building in seismic design published by AIJ suggested the following equations to evaluate the ultimate flexural strength of RC columns subjected to seismic loads. Depending on different reinforcement at cross section, the model can be shown as follows,

When the number of longitudinal steel rebars at tensile zone is less than 3 ,

$$
M_{u}=\left\{\begin{array}{cc}
0.8 a_{L t} f_{y l} d+0.4 P d & N_{\min } \leq P<0 \\
0.8 a_{L t} f_{y l} d+0.5 P d\left(1-\frac{P}{b d f_{c}^{\prime}}\right) & 0 \leq P<0.4 b d f_{c}^{\prime} \\
\left(0.8 a_{L t} f_{y l} d+0.12 b d^{2} f_{c}^{\prime}\right)\left(\frac{N_{\max }-P}{N_{\text {max }}-0.4 b d f_{c}^{\prime}}\right) & 0.4 b d f_{c}^{\prime} \leq P<N_{\max }
\end{array}\right.
$$

When the number of longitudinal steel rebars at tensile zone is greater than 2,

$$
M_{u}=\left\{\begin{array}{lr}
0.5 a_{g} f_{y l} g_{1} d+0.5 P g_{1} d & N_{\min } \leq P<0 \\
0.5 a_{g} f_{y l} g_{1} d+0.5 P d\left(1-\frac{P}{b d f_{c}^{\prime}}\right) & 0 \leq P<N_{b}=0.22\left(1+g_{1}\right) b d f_{c}^{\prime} \\
\left(0.5 a_{g} f_{y l} g_{1} d+0.024\left(1+g_{1}\right)\left(3.6-g_{1}\right) b d^{2} f_{c}^{\prime}\right)\left(\frac{N_{\max }-P}{N_{\max }-0.22\left(1+g_{1}\right) b d f_{c}^{\prime}}\right) & N_{b} \leq P<N_{\max }
\end{array}\right.
$$

where, $N_{\min }$ is the ultimate axial tension capacity of RC columns which can be taken as $N_{\min }=-a_{g} f_{y l}$; and $N_{\max }$ is the ultimate axial compressive capacity of columns calculated as $N_{\max }=b d f_{c}^{\prime}+a_{g} f_{y l}$;

\subsection{Shear capacity}

\section{Code/guideline models: ACI 318 [11], ASCE-ACI 426[18] and JSCE models [19]}

ACI 318 model and ASCE-ACI 426 proposal both considered that the shear strength of RC columns consists of concrete shear contribution $V_{c}$ and truss-mechanism $V_{s}$ depending mainly on transverse reinforcement. In this paper, the feasibilities of the two models are examined with a 
consideration that the total effect of fibre on concrete can be taken into account in the compressive strength of FRC [14]. In addition, Japan Society of Civil Engineering (JSCE) [19] recommended a specialized calculation formula to evaluate the shear strength of FRC columns by introducing an enhancing factor into the shear contribution of normal concrete. The details of these models are listed in Table.1.

\section{Lee model [20]}

Lee [20] investigated the evaluation accuracies and reliabilities of some representative shear strength models or proposals of RC column when they are used in FRC columns. They include ACI 318, AIJ, NZS 3101, Hirosawa [17] and Priestley et al. models [21]. His results indicated that Priestley et al. model shows a high potential feasibility to evaluate the shear strength of FRC columns. According to the comparative analysis of these models and the reconsideration of original Priestley et al. model, as well as using his experimental results of FRC columns with different steel fibre volume fractions, Lee proposed a calculation equation to quantify the shear contribution of steel fibre $\left(V_{f}\right)$ to the total shear strength, which can be calculated as,

$$
V_{f}=0.146 \rho_{F} \sqrt{f_{c}^{\prime}} b d
$$

Table 1 Some representative shear models and proposals for RC/FRC columns

\begin{tabular}{|c|c|c|}
\hline Codes/Models & Ultimate Shear equations & Notes \\
\hline ACI-318 & $V_{n}=V_{c}+V_{s}=0.166\left(1+\frac{P}{13.8 A_{g}}\right) \sqrt{f_{c}^{\prime}} b d+\frac{A_{v} f_{y t} d}{S}$ & \\
\hline ASCE-ACI 426 & $V_{n}=V_{c}+V_{s}=v_{b}\left(1+\frac{3 P}{f_{c}^{\prime} A_{g}}\right) b d+\frac{\pi}{2} \frac{A_{v} f_{y t} d}{S}$ & $v_{b}=\left(0.067+10 \rho_{T}\right) \sqrt{f_{c}^{\prime}} \leq 0.2 \sqrt{f_{c}^{\prime}}$ \\
\hline JSCE & $V_{n}=(1+\kappa) V_{c}+V_{s}=(1+\kappa) f_{v c d} \sqrt[4]{\frac{1000}{d}} \sqrt[3]{100 \rho_{L t}} b d+\frac{A_{v} f_{y t}}{s}\left(\frac{7 d}{8}\right)$ & $\kappa=1.0, f_{v c d}=0.2 \sqrt[3]{f_{c}^{\prime}} \leq 0.67$ \\
\hline $\begin{array}{l}\text { Nagasaka et al. } \\
\text { model }\end{array}$ & $V_{n}=\left(k_{u} k_{p} \frac{0.115\left(f_{c}^{\prime}+17.6\right)}{a / d+0.12}+0.85 \sqrt{\rho_{T} f_{y t}}+k_{f} \sqrt{\rho_{F}}+0.1 \sigma_{0}\right) b j$ & $\begin{array}{l}k_{u}=0.91 ; k_{p}=0.82\left(\rho_{L t}\right)^{0.23} \\
j=7 d / 8 ; k_{f}=6.9\end{array}$ \\
\hline Lee model & $V_{n}=\left(0.29+0.146 \rho_{F}\right) \sqrt{f_{c}^{\prime}} b d+\frac{d-c}{2 a} P+\frac{A_{v} f_{y t} d^{\prime} \cot 30^{\circ}}{S} ;$ & $c=0.25 \sim 0.35 d$ \\
\hline $\begin{array}{l}\text { Huang et al. } \\
\text { model }\end{array}$ & $V_{n}=B \sqrt{f_{F R C}^{\prime}} \sqrt{1+\frac{n \sqrt{f_{F R C}^{\prime}}}{B}} A_{e}^{\prime}+\frac{A_{s t} f_{y t} d}{S}$ & $\begin{array}{l}A_{e}^{\prime}=b\left(d-a_{s}\right) f_{F R C}^{\prime}=k_{h f} k_{s} f_{c}^{\prime} \\
k_{h f c}=1+0.206 \rho_{F}+0.388 \rho_{F p}\end{array}$ \\
\hline
\end{tabular}

\section{Huang et al. model [22]}

Based on the experimental investigation of 24 FRC columns made of steel-polypropylene hybrid fibre, Huang et al. reported that the strain of stirrups perpendicular to loading direction is rather small. For this, they suggested the stress of stirrups in the direction can be ignored and proposed a simplified plane stress model to determine the shear component of FRC $\left(V_{f r c}\right)$. Besides, the model considered that concrete normal stress $\sigma_{\mathrm{x}}$ is about 0.067-0.1 $\sigma_{y}$ (even at ultimate limit state) which can be ignored in the calculation of shear strength. On the other hand, their test observations shown that the major degree of shear cracks of FRC columns ranges from 37 to $45^{\circ}$, with respect to the direction of longitudinal reinforcement, as shown in Fig.1 (g) and (h). 
Therefore, they suggested that the shear capacity of stirrups $V_{s}$ should be calculated using a $45^{\circ}$ truss model adopted by ACI 318 model (see Table.1).
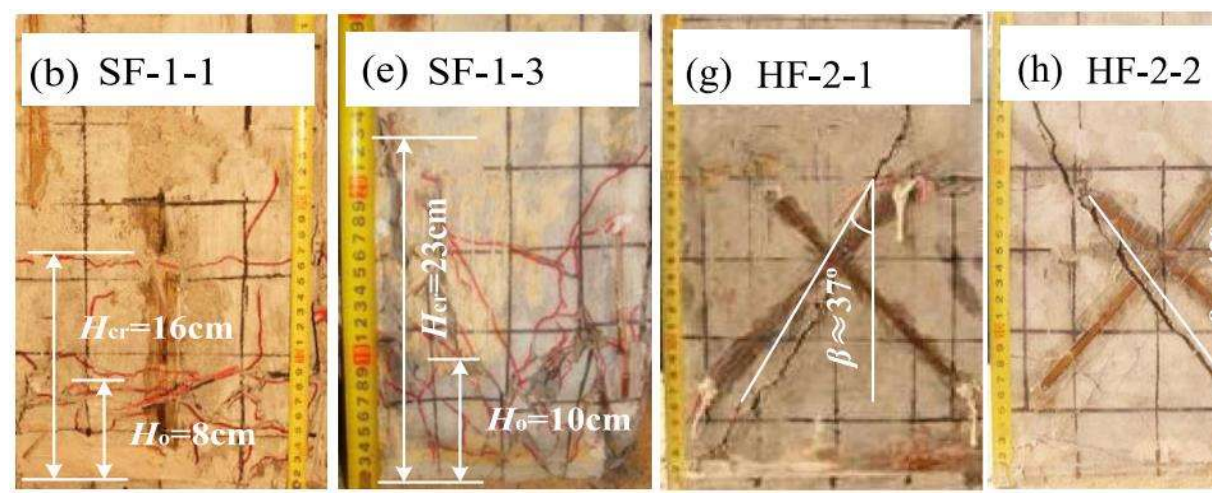

Fig.1 Examples of three failure modes of FRC columns [22]

\section{Nagasaka model [23]}

In Japan, Ohno-Arakawa model [24] is well known because it has explained clearly the shear transfer mechanism of RC columns and presented a good evaluation agreement with experimental results at the early stage. Based on this, through some further test investigations, some researchers have modified this model. For example, a modified Ohno-Arakawa model developed by Hirosawa has been recommended by AIJ [17] to calculate the shear strength of RC columns subjected to seismic loads. This model has considered more structural factors affecting the seismic shear behaviour of RC columns. Moreover, considering the effect of fibre on concrete, Nagasaka et al. [23] modified original Ohno-Arakawa model to evaluate the shear strength of FRC columns subjected to seismic loads through test studies and obtainable database analyses. In the model, a shear component related to the volume fraction of fibre was introduced, as shows in Equation (7). The details of this model are listed in Table.1.

$$
V_{f}=6.9 \sqrt{\rho_{F}} b j
$$

\section{Development of database of FRC columns subjected to seismic loads}

In order to investigate the reliability of the existing shear models of FRC/RC columns listed in Table.1, this study builds a comprehensive seismic research database of FRC columns. It contains the main results of existing experimental investigations focusing on seismic behaviour of FRC columns as much as possible such as ultimate strengths, deformation, (initial) stiffness, failure modes and others, which will be reported at elsewhere in detail. These laboratory investigations have usually been performed under simulated seismic loads, i.e. through a combined loads consisting of a constant axial load and reversed lateral load according to certain cycling rules (usually specified by notional standard test) [e.g. 2, 20, 22]. These loading ways are obtained from the plentiful research experience or collected earthquake record data.

\subsection{History and characteristic of FRC research}


Since fibre was reported that it can be used in concrete as the fifth composition, numerous experimental endeavours have been performed in all the parts of the world. Table.2 lists the overview of previous studies regarding FRC obtained from a literature investigation in Web of Science. As shown in this table, most of studies have been performed in UAS, China and Canada. The research focusing on the flexural and shear properties of FRC members have been reported firstly since 1970s and 1980s respectively. Subsequently, as an important beginning, Tang et al. [25] investigated the properties of FRC columns subjected to seismic loads in 1992. On the other hand, it is very clear that the most used fibre in the reported FRC members is steel fibre. At the same time, there are just limited studies focused on the seismic behaviour of FRC columns, especially about seismic shear behaviour.

Table 2 Overview of previous studies on fibre concrete since 1968

\begin{tabular}{clccccc}
\hline \multirow{2}{*}{ No. Key words of topic } & \multirow{2}{*}{ Refine } & Number of & Start & & \multicolumn{2}{c}{ Countries } \\
\cline { 4 - 6 } & & references & year & No.1 & No.2 & No.3 \\
\hline 1 & & 37311 & 1968 & USA & PR China Canada \\
2 & shear & 5426 & 1982 & USA & PR China Canada \\
3 & flexure & 828 & 1977 & USA & PR China & Italy \\
4 & seimsic, earthquake & 403 & 1991 & USA & PR China Canada \\
5 & fiber, concrete & column & 3314 & 1982 & USA & PR China Canada \\
6 & column+shear & 695 & 1982 & USA & PR China Canada \\
7 & column+flexure & 94 & 1991 & USA & PR China Italy \\
8 & column+seismic, earthquake & 267 & 1992 & USA & PR China Canada \\
9 & column+seismic, earthquake+shear & 100 & 1992 & USA & PR China Canada \\
10 & column+seismic, earthquake+flexure & 8 & 1992 & USA & PR China & Turkey \\
11 & steel fiber concrete & - & 14831 & 1974 & USA & PR China Canada \\
12 & glass fiber concrete - & 7341 & 1977 & USA & Canada PR China \\
\hline
\end{tabular}

Timespan: All years. The database is up to 2016-05-17;

Indexes: SCI-EXPANDED, SSCI, A\&HCI, CPCI-S, CPCI-SSH, BKCl-S, BKCl-SSH, CCR-EXPANDED, IC.

\subsection{Database development and characteristic}

Aiming to clearly understand the ultimate resistance and deformation capacities of FRC columns subjected to seismic loads, this paper collects 322 FRC columns subjected to a constant axial load and reverse lateral loads which cover most, if not all, of experimental investigations mainly reported by USA, China, Canada and Japan. Most of the collected FRC columns used steel fibre same as described in Table 2. All specimens have rectangular section and use small scale size. In this database, the 322 rectangular FRC columns can be divided into three groups according to their ultimate failure modes, i.e. flexure (F), flexure-shear (F-S) and shear (S) modes. The method proposed by structural performance database in PEER [26] is used to distinguish the failure modes of FRC columns. Fig.1 shows some examples of three failure modes reported by Huang et al. [22]. Besides, the shear failure mode in this study includes shear-tensile, shear-compressive and shear failure modes with horizontal shear damage or anchorage zone damage. At the same time, if some obvious shear diagonal cracks are observed in certain FRC column according to available damage descriptions or pictures in the literature, this column also is judged as S or F-S failure modes depending on the yielding of reinforcements. 
Table. 3 summarizes the varying rang of main experimental variables of the database, while Fig.2 shows the distribution of these variables with different failure modes. The primary parameters include shear span ratio $(a / d)$, concrete compressive strength $\left(f_{c}\right)$, fibre volume fraction $\rho_{F}$, transverse and longitudinal steel ratios $\left(\rho_{T}\right.$ and $\left.\rho_{L}\right)$, and axial load ratio $(n)$ etc. There was only one experimental investigation reported by Makitani et al [27] concerning the effect of the rate of lateral loading on the seismic behavior of FRC columns. In addition, a kind of steel-polypropylene hybrid fibers was used in FRC columns reported by Huang et al [22]. In these studies, the maximum applied volume fraction of fiber in concretes is $3.0 \%$ (see Table.4), which is same as the one suggested by most of practical guidelines; and the maximum axial load ratio is less than 0.6 which also satisfies the provisions in most of design codes such as AIJ guideline (upper limit is 0.76 ).

Table 3 Primary experimental variables in the database

\begin{tabular}{|c|c|c|c|c|c|c|c|}
\hline \multirow{3}{*}{ Main variables } & \multicolumn{7}{|c|}{ Variable range } \\
\hline & \multirow{2}{*}{$\begin{array}{l}\text { Failure } \\
\text { modes }\end{array}$} & \multicolumn{2}{|c|}{ Fexlure } & \multicolumn{2}{|c|}{ Fexlure-shear } & \multicolumn{2}{|c|}{ Shear } \\
\hline & & Min & Max & Min & Max & Min & Max \\
\hline The number of column & & \multicolumn{2}{|c|}{89} & \multicolumn{2}{|c|}{39} & \multicolumn{2}{|c|}{194} \\
\hline Depth/Diameter D & $(\mathrm{mm})$ & 140 & 260 & 152 & 260 & 150 & 400 \\
\hline Shear span ratio & $(\mathrm{a} /)$ & 1.0 & 10.7 & 1.0 & 5.8 & 1.0 & 5.8 \\
\hline Concrete compression strength & $(\mathrm{MPa})$ & 21.2 & 81.1 & 18.3 & 158.0 & 21.2 & 75.6 \\
\hline Fiber ratio (volume ratio to concrete) & $(\%)$ & 0 & 3 & 0 & 2 & 0 & 2 \\
\hline Fiber tensile strength & $(\mathrm{MPa})$ & 0 & 1600 & 0 & 1600 & 0 & 1170 \\
\hline Transverse steel yielding strength & $(\mathrm{MPa})$ & 0 & 542 & 262 & 1473 & 0 & 573 \\
\hline Transverse steel ratio (area) & $(\%)$ & 0.00 & 2.44 & 0.28 & 1.47 & 0.00 & 0.81 \\
\hline Spacing of shear steel S & $(\mathrm{mm})$ & 0 & 140 & 2 & 130 & 0 & 600 \\
\hline Normalized Spacing of shear steel & $(S / D)$ & 0.00 & 0.70 & 0.10 & 0.65 & 0.00 & 2.31 \\
\hline Longtudinal steel yielding strength & (Mpa) & 336 & 575 & 365 & 716 & 350 & 575 \\
\hline Longtudinal steel ratio (area) & $(\%)$ & 1.00 & 2.55 & 1.00 & 3.08 & 0.97 & 4.25 \\
\hline Axial load ratio & (n) & 0.00 & 0.50 & 0.07 & 0.43 & 0.00 & 0.60 \\
\hline
\end{tabular}

Regarding the distrubition of main structural factor, as shown in Fig.2(g), the addition of fiber can not prevent brittle shear failure in FRC columns, even the used fibre has a very high yielding strength (see Fig.2. (d)). This indicates that the shear component provided by fibre is limited which can be explained by the discontinuity of the fibers in concrete that leads to them can not provide a similar shear resisting action as the ones provided by shear reinforcment, especially when incline cracks get widther or fibre has a smaller aspect ratio. Besides, just a few studies can be available which concerned the shear failure and ultimate strength of FRC columns using high strength concrete or under high axial load. At the same time, the figure also shows an improtant obversation that about $90 \%$ of shear failure occur in the specimens with a shear span ratio of less than 3.0 or the ratio of transverse reinforcements of less than $0.5 \%$. This is very helpful to structural designers for this can be considered as a priliminary assessment method to predicte the potential failure modes of FRC columns. The detailed method for assessing the failure mode of FRC columns will be discussed in detail, soon afterwards. 
In summary, the main characteristics of the seismic research database of FRC columns under seismic loads are listed as follows:

1) The minimum and maximum compressive strength of concrete are $18.3 \mathrm{MPa}$ and $158 \mathrm{MPa}$ respectively; $51 \%$ of specimens have a compressive strength of more than $25 \mathrm{MPa}$.

2) Most of specimens use steel fiber, expect for 15 columns applied steel-Polypropylene hybrid fiber and 9 FRC columns use synthetic or polypropylene fiber (see Table.4).

3) Eighty-seven percent of specimens have a transverse steel ratio of more than $0.2 \%$.

4) The overall depth of all columns in this database exceed $140 \mathrm{~mm}$ and Eighty-two present of these specimens have an overall depth of 200 to $300 \mathrm{~mm}$.

5) All of the specimens have a shear span ratio of at least 1.0. 71\% of these specimens have a shear span ratio of 1.5 to 2.0 and $22 \%$ of the specimens have a shear span ratio of 2.0 to 4.0;

6) This database includes 14 FRC columns without transverse reinforcement, and 36 FRC columns with axial load ratio of 0.0 and 86 RC columns using $0.0 \%$ fiber ( $33 \boldsymbol{F}$ columns, $13 \boldsymbol{F}$ - $\boldsymbol{S}$ columns and $40 S$ columns).
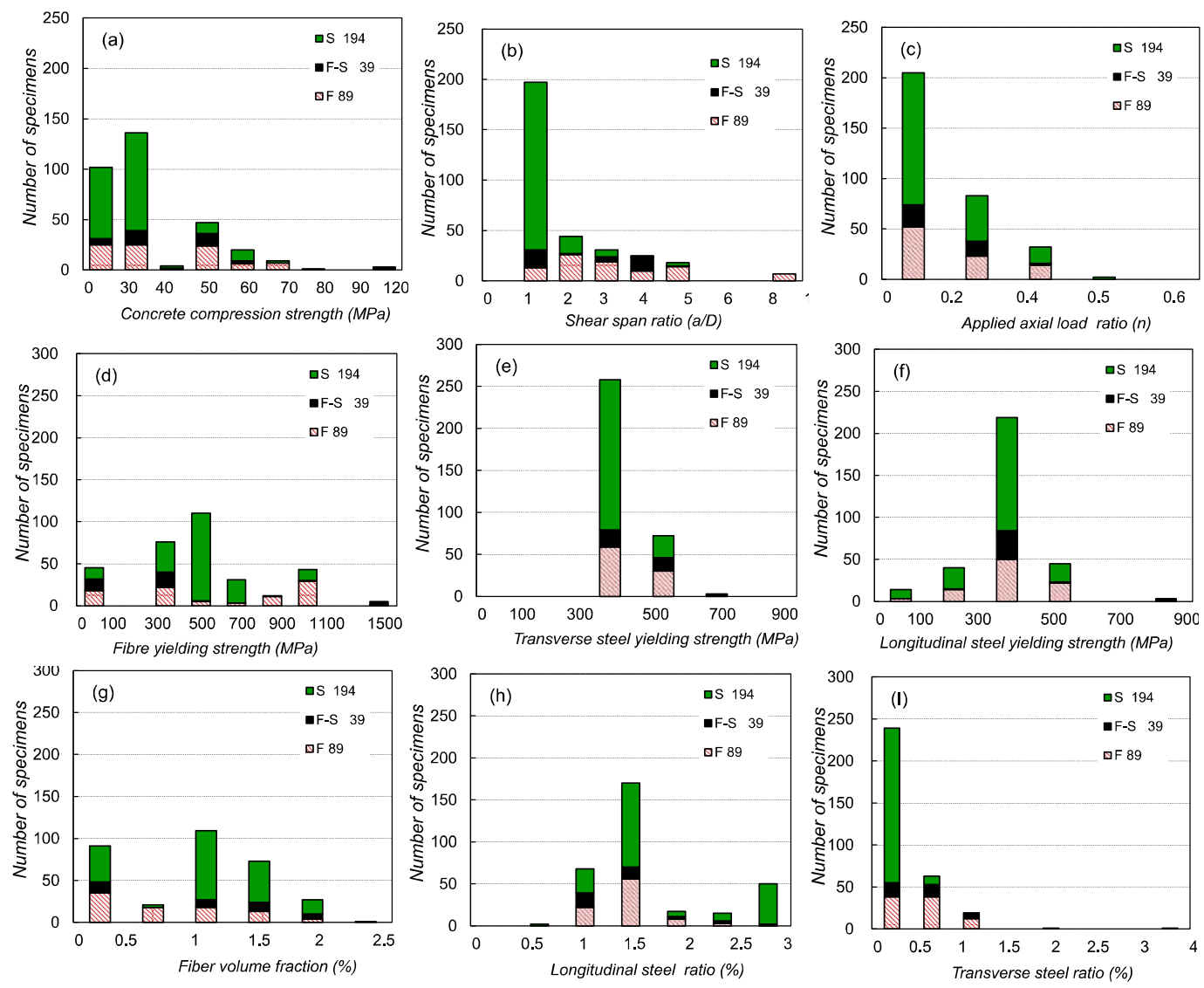

Fig.2 Distribution of main variables with different failure modes 
Table 4 Properties of used fibre in the database

\begin{tabular}{ccccc}
\hline References & Fibre type & $\begin{array}{c}\text { Number of } \\
\text { specimen }\end{array}$ & $\begin{array}{c}\text { Fiber yielding strength } \\
\text { (Mpa) }\end{array}$ & $\begin{array}{c}\text { Fibre volume } \\
\text { fraction }\end{array}$ \\
\hline $1-14,16,18-23,25-29$ & Steel fibre & 298 & $0-1170$ & $0-3 \%$ \\
15 & Synthetic fiber & 6 & $0-1600$ & $0-2 \%$ \\
15 & Steel-Polypropylene & 15 & $400-500$ & $0-1.5 \%$ \\
17 & Polypropylene fiber & 3 & 400 & $0.15 \%$ \\
\hline
\end{tabular}

\subsection{Effects of variables on ultimate strengths of FRC columns}

Fig.3 shows the effects of main variables on the seismic ultimate strengths of FRC columns including flexural and shear strengths. In this figure, the ultimate lateral resisting forces represent the ultimate shear and flexure strengths of columns depending on the different failure modes of the corresponding FRC columns, respectively. Results show that shear span ratio, axial load ratio, concrete compressive strength, longitudinal steel and fibre volume fraction all have a significant influence on the ultimate flexural strength of FRC columns. With regards to the shear strength of FRC columns, the main affecting factors are concrete compressive strength, shear span ratio and transverse steel ratio. According to Figs.3 and 4, the detailed analyses can be summarized as follows:

\section{In term of shear resistance:}

(1) Similarly as normal reinforced concrete columns, the shear capacities ( $\boldsymbol{V}$ ) of FRC columns reduces drastically with shear span ratio;

(2) Because the major shear contribution of RC column usually is from truss mechanism, transverse reinforcement also presents a significant influence on the shear strength of FRC column, i.e. $\boldsymbol{V}$ increases drastically as transverse reinforcement ratio. Besides, when the yielding strength of transverse reinforcement increases (up to 600MPa), the shear strength of FRC column increases.

(3) When the axial load ratio of FRC columns increased (up to 0.6), the shear strengths of columns increase. Similar to normal RC columns, it can be attributed to the arch action in RC column provided by axial load. When applied axial load is too large, however, the $P$ - $\Delta$ effect caused by axial load changes into a major negative factor affecting shear resistance capacity of columns.

(4) The shear strengths of FRC columns decrease as the normalized spacing of shear steel $S / d$, which also can be found in normal RC columns [e.g. 28].

(5) Regarding the influence of fibre, as shown in Fig.3, the shear strengths of FRC columns increase as the volume fractions of fibre increase.

(6) On the other hand, as indicated in Fig.4 (a), when fibre was added into concrete, one of important findings is that the shear strengths of FRC columns increase linearly as lateral confinement indexes (including fibre enhancing index $\rho_{F} f_{y f} / f_{c}^{\prime}$ and shear steel index $\rho_{T} f_{y t} / f_{c}^{\prime}$ ). It indicated that fiber can provide partly lateral confinement for FRC columns subjected to seismic loads.

\section{In term of flexural resistance:}


(1) The increasing of concrete compressive strength can provide a positive effect on the flexural resistance of FRC columns which also has verified in CEB-FIP MC90 and AIJ flexural models.

(2) The results plotted in Fig.3 proved that an increasing axial load ratio (up to $0.5 f_{c}^{\prime} A g$ ) has resulted in an increase in flexural resistance capacity of FRC columns.

(3) If FRC column has a larger section dimension or higher longitudinal reinforcement ratio, a higher flexural strength can be presented in the column.

(4) Regarding the influence of fibre, as shown in Fig.3, the flexural strength of FRC column increases as the volume fraction of fibre increases in concrete.

(5) Fig.4 (b) implies that transverse steel ratio has an influence on the moment capacity of FRC columns. This is because a high lateral confinement normally can improve the resisting to the flexural deformation of $\mathrm{RC}$ columns by preventing the spalling of cover concrete to improve the total ductility of member.
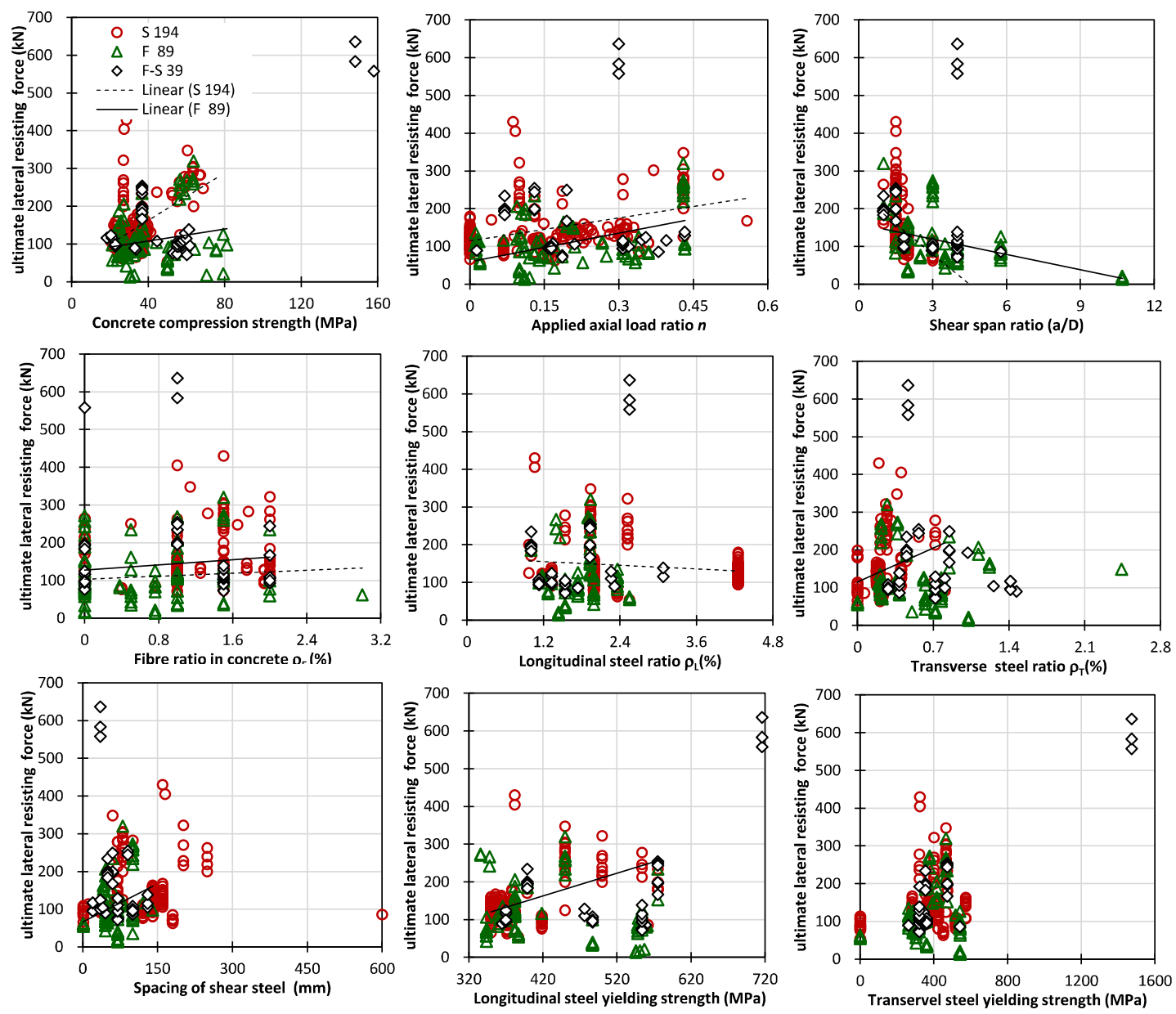

Fig.3 Main variables and ultimate strength of FRC columns 

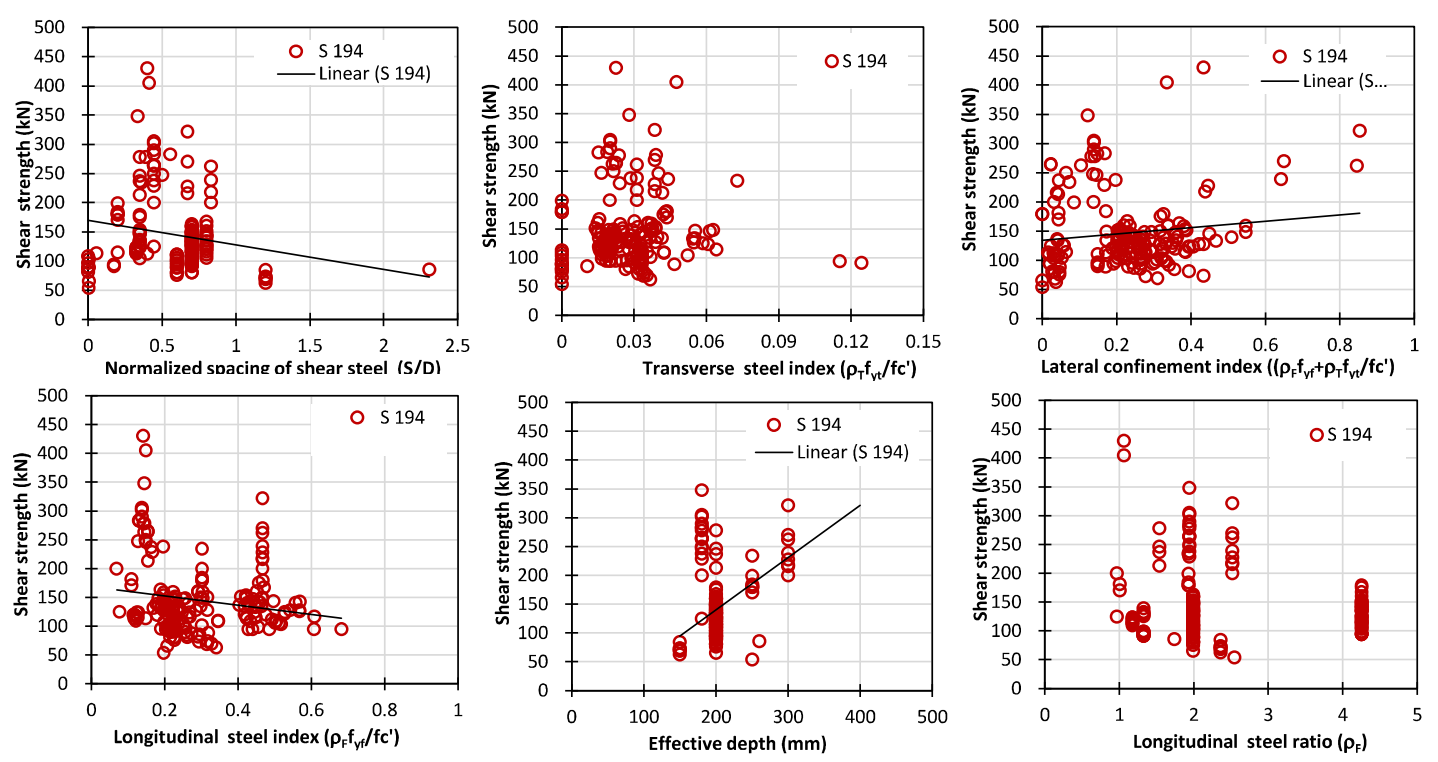

(a) Shear strength of FRC columns
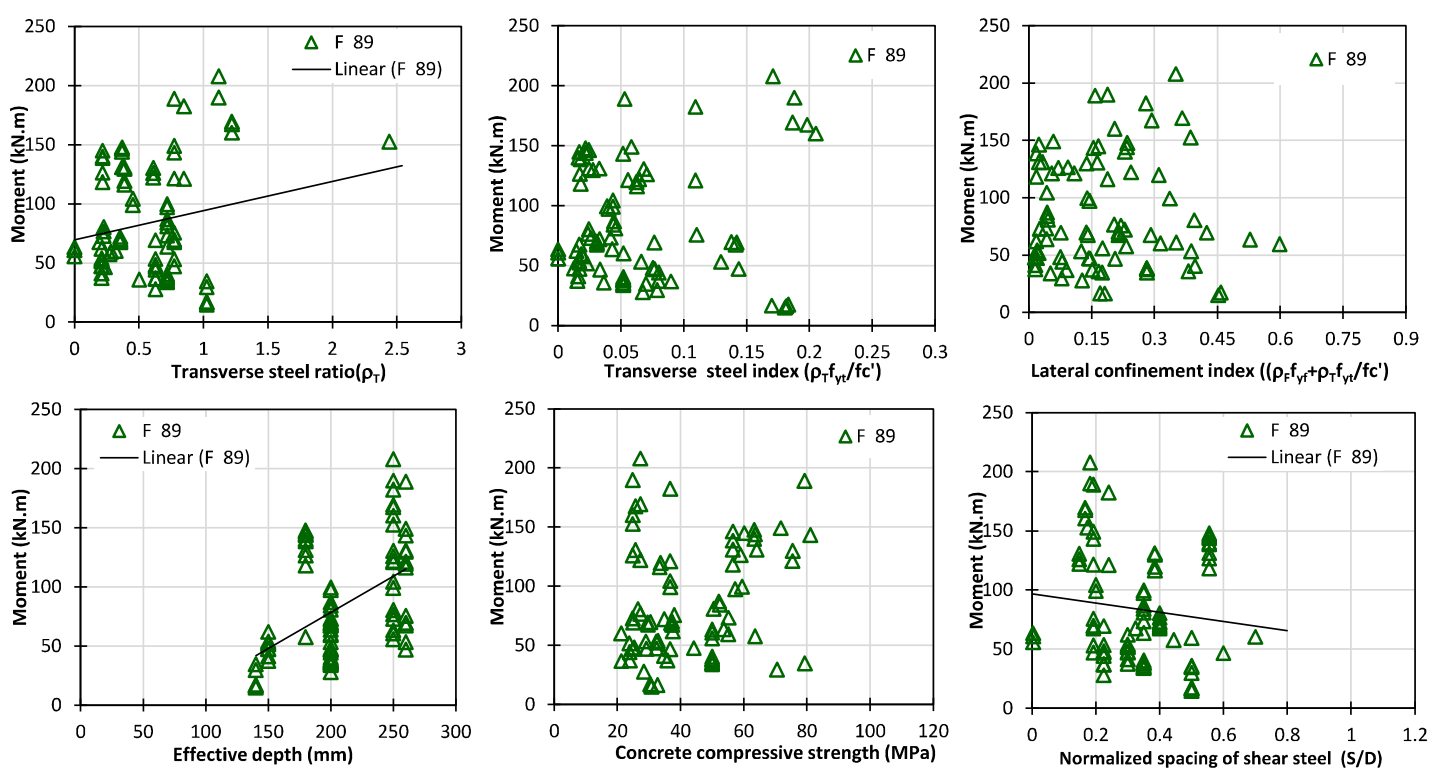

(b) Moment of FRC columns

Fig.4 Ultimate strengths and other key factors

\subsection{Effect of fibre on ultimate seismic strengths of RC columns}

As described previously, many studies indicated the addition of fibre will be beneficial to the deformation property and strength development of RC columns. Based on the database reported above, this fact is verified by the experimental results as shown in Figs.5 and 6, which can present more clear understanding regarding the effect of fibre on the two strengths of RC columns, respectively. The results plotted in Fig.5 show that fibre in concrete has a stable and linear influence on the shear strength of RC columns. Between different series of experimental investigations, the enhancement ratios of shear strength caused by fibre have a high level of 
similarity. This also clearly suggests that the enhancing effect of fibre on shear strength of concrete columns should be considered in the shear design of FRC columns. On the other hand, in term of flexural strength, although the increase ratio of the flexural strength from fibre is different in different series of studies, the positive effect of fibre on this strength of FRC columns is still clearly presented in Fig.6. According to these references list in Fig.6, the enhancement of fibres to flexural strength of RC columns can be mainly contributed on that fibre can improve the ductility, spalling of cover concrete and cracking resistance of columns.

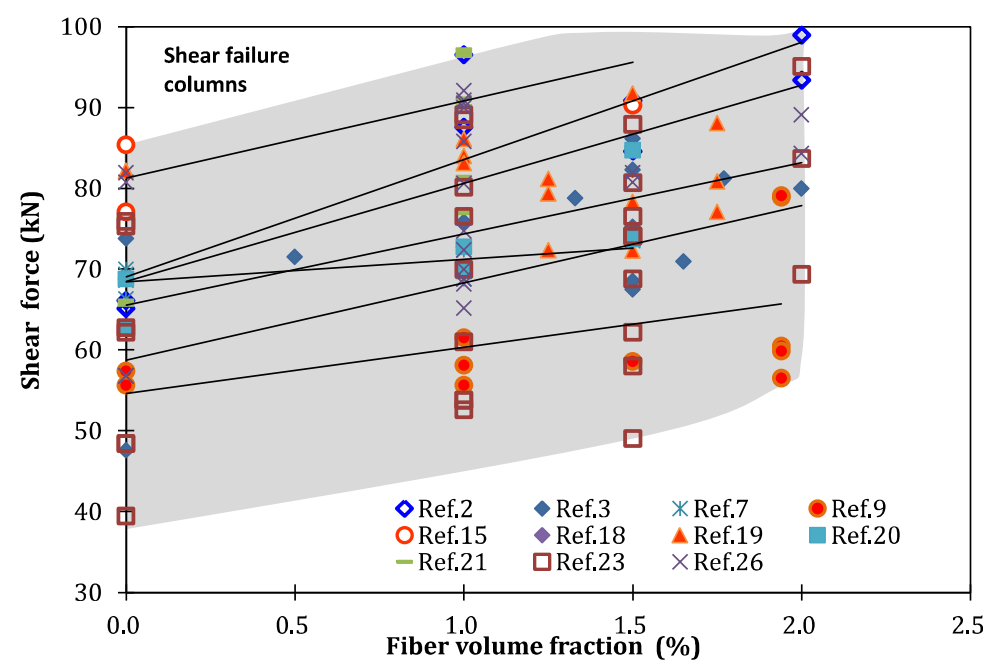

Fig.5 Effect of fibre on shear strength of FRC columns

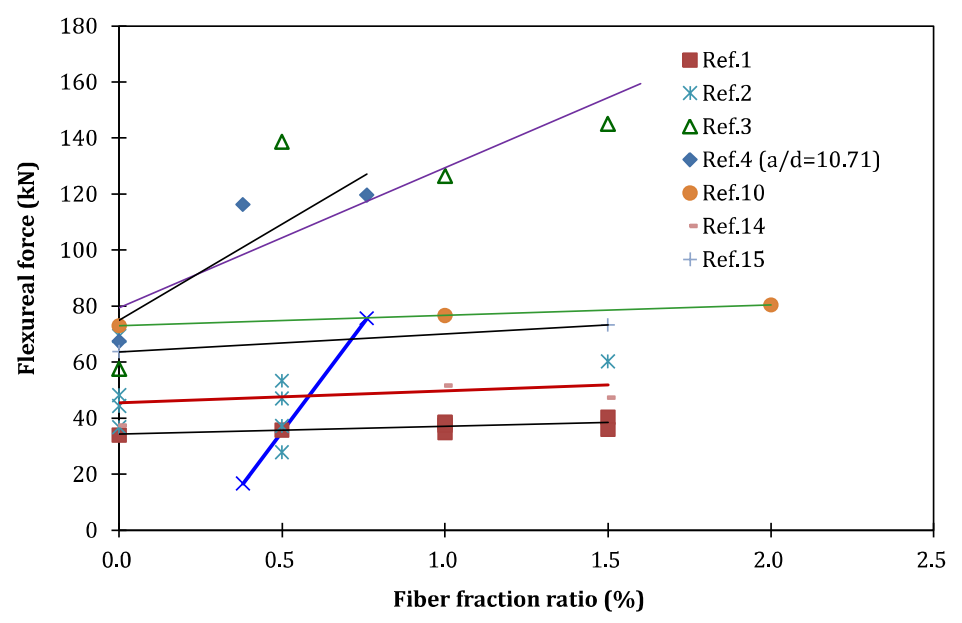

Fig.6 Effect of fibre on flexural strength of FRC columns

\section{Discussions and proposals of ultimate capacities}

Using the database, the following sections will examine and discuss existing ultimate shear and flexural models of FRC/RC column. It is well known that the cyclic behaviour of RC (or FRC) column depends on some factors such as the bond decay of concrete-steel interface, the post-buckling or fracture of longitudinal reinforcements, the confinement effect of columns and the maximum amplitude of a cyclical imposed displacement. However, it should be noted that the 
ultimate strengths concerned by this paper are the maximum experienced shear and flexural forces obtained from the hysteresis curve results of FRC columns in the corresponding literature (mean value of both directions). Besides, the influences of repeated load and $P-\Delta$ effect on the calculation of strengths have already been considered, which is same as other research [e.g. 20,22].

\subsection{Ultimate shear capacity - comparison and modification}

To evaluate the accuracies and reliabilities of the above existing shear strength models in Section 2, the strength ratio of experimental shear strength to calculated strength: $V_{\text {exp }} / V_{c a l}$ is used in this paper. If the ratio is greater than 1.0, that means the predicted shear strength is less than experimental one which implies the model is conservative for this specimen. In order to use the formulas, the strength of material in these equations is measured average strength obtained from the literature. In this paper, the predicted shear strengths $V_{c a l}$ of the models are calculated under a consideration of all of the strength reduction factors are taken as 1.0.

In addition, in order to assess the existing shear models in FRC columns systematically, several main statistical evaluation factors are used. They include minimum, maximum, mean strength ratio, standard deviation (St. Dev), coefficient of variation $(\mathrm{CoV})$, the coefficient of determination $\left(R^{2}\right)$ and the mean absolute error $(M A E)$ of strength ratios of $V_{\text {exp }} / V_{\text {cal. }}$. Normally, if the mean of strength ratios of one modal is close to 1.0 with small standard deviation, it indicates this model can predict the experimental results well. The value of $\mathrm{CoV}$ is known as relative standard variation and is usually used to evaluate the accuracy of predicted results or repeatability of an assay. A low $\mathrm{CoV}$ means a small amount of scatter occur in predicted results. $M A E$ is a factor which is used to measure how close the predictions are to eventual outcomes, i.e. it can be used to evaluate the total errors computed by model. Besides, coefficient of determination $R^{2}$ is a factor to evaluate whether the model can be used for providing accurate predicting results, or how well analysed data fits a statistical model-sometimes simply a line or curve. If $R^{2}$ is near to 1.0 , meaning the calculation model can accurately predict experimental results. It should be noted that when calculated results have a low linear relation with a reference line (e.g. $V_{\text {exp }}=V_{c a l}$ ), the evaluation of coefficient of determination will be meaningless. The above calculation equations of $\mathrm{CoV}, M A E$ and $R^{2}$ can be presented by the followings,

$$
\begin{aligned}
& \operatorname{CoV}(\%)=\frac{S t . D e v}{\text { Mean }} \times 100 \\
& \operatorname{MAE}(\%)=\frac{1}{n} \sum_{i=1}^{n} \frac{\left|V_{\exp i}-V_{c a l, i}\right|}{V_{\exp i}} \times 100 \\
& R^{2}=1-\sum_{i=1}^{n} \frac{\left(V_{\text {exp } i}-V_{\text {cal }, i}\right)^{2}}{\left(V_{\text {exp } \dot{ }}-\bar{V}_{\text {exp }}\right)^{2}} \quad 0 \leq R^{2} \leq 1.0
\end{aligned}
$$

The comparisons of the experimental strengths to predictions computed by various shear models are presented in Fig.7, while the detailed statistics results are summarized in Table.5 and 
Fig.8. In this table, Lee model uses a compressive zone of $35 \%$ of effective section depth $(0.35 d)$ proposed by Kowalsky and Priestley [29], considering the enhancing effect and crack-resisting improvement of fibre to $\mathrm{RC}$ column. Comparing with this, the predictions are more conservative if $0.25 d^{\prime}$ was used. The characteristics of the predicated shear strength ratio of these shear failure FRC columns are summarized, as follows:

a) The mean values of all models are larger than 1.0 except for Hung et al. model, especially ACSE-ACI model, ACI 318 and JSCE code models. It means the predications of most of existing models are conservativeness.

b) Although Lee model and Hung et al. model both have a good mean value of nearing to 1.0, the values of St.Dev, CoV, MAE of the two models still need to be improved;

c) The standard deviation levels of most of the models are greater than 0.50 , except for Hung et al. model and Lee model. The maximum and minimum values of St. Dev values are 1.48 and 0.23 presented in ASCE-ACI and Hung et al. models, respectively.

d) The results of $R^{2}$ indicate that most of the models can not present a good predictions comparing with experimental results, expect for ones of Hung et al. and Lee models which can reach a relative 0.26 and 0.64 , respectively.

e) The $\mathrm{CoV}$ values of ASCE-ACI, JSCE and Nagasaka et al. models are higher than other models', are $57.51 \%, 35.99 \%$ and $32.48 \%$ respectively; Besides, the values of the other models all are near to $25 \%$ meaning the predicted results from these models have a relative smaller scatter (see Fig.8).

f) The values of $M A E$ of all the models range from $20.5 \%$ to $54.3 \%$. Lee model has the smallest $M A E$ meaning the predictions of the model are close to the experimental ones, and the MAEs of other models are greater than $30 \%$ (see Fig.8).

g) Comparing with the accuracy and discreteness of these models comprehensively, Lee model presents a relative good evaluation result. However, the reliability of this model still needs to be improved.

Table.5 Statistical comparative results of the existing shear strength models

\begin{tabular}{|c|c|c|c|c|c|c|c|}
\hline \multirow{2}{*}{\multicolumn{2}{|c|}{ Models }} & \multirow{2}{*}{ ASCE-ACI } & \multirow{2}{*}{ ACI } & \multirow{2}{*}{ JSCE } & \multirow{2}{*}{ Nagasaka et al. } & \multirow{2}{*}{ Hung et al. } & \multirow{2}{*}{$\begin{array}{c}\text { Lee } \\
c=0.35 d^{\prime}\end{array}$} \\
\hline & & & & & & & \\
\hline \multirow{4}{*}{$\mathrm{V}_{\mathrm{exp}} / \mathrm{V}_{\mathrm{cal}}$} & Minimum & 0.63 & 0.74 & 0.50 & 0.96 & 0.31 & 0.46 \\
\hline & Maximum & 8.91 & 3.17 & 3.46 & 3.87 & 1.58 & 1.96 \\
\hline & Mean & 2.57 & 2.01 & 1.50 & 1.70 & 0.87 & 1.09 \\
\hline & St.Dev & 1.48 & 0.50 & 0.54 & 0.55 & 0.23 & 0.28 \\
\hline \multicolumn{2}{|c|}{$\begin{array}{c}\text { Coefficient of } \\
\text { determination } \mathrm{R}^{2}\end{array}$} & 一 & - & - & - & 0.26 & 0.64 \\
\hline
\end{tabular}



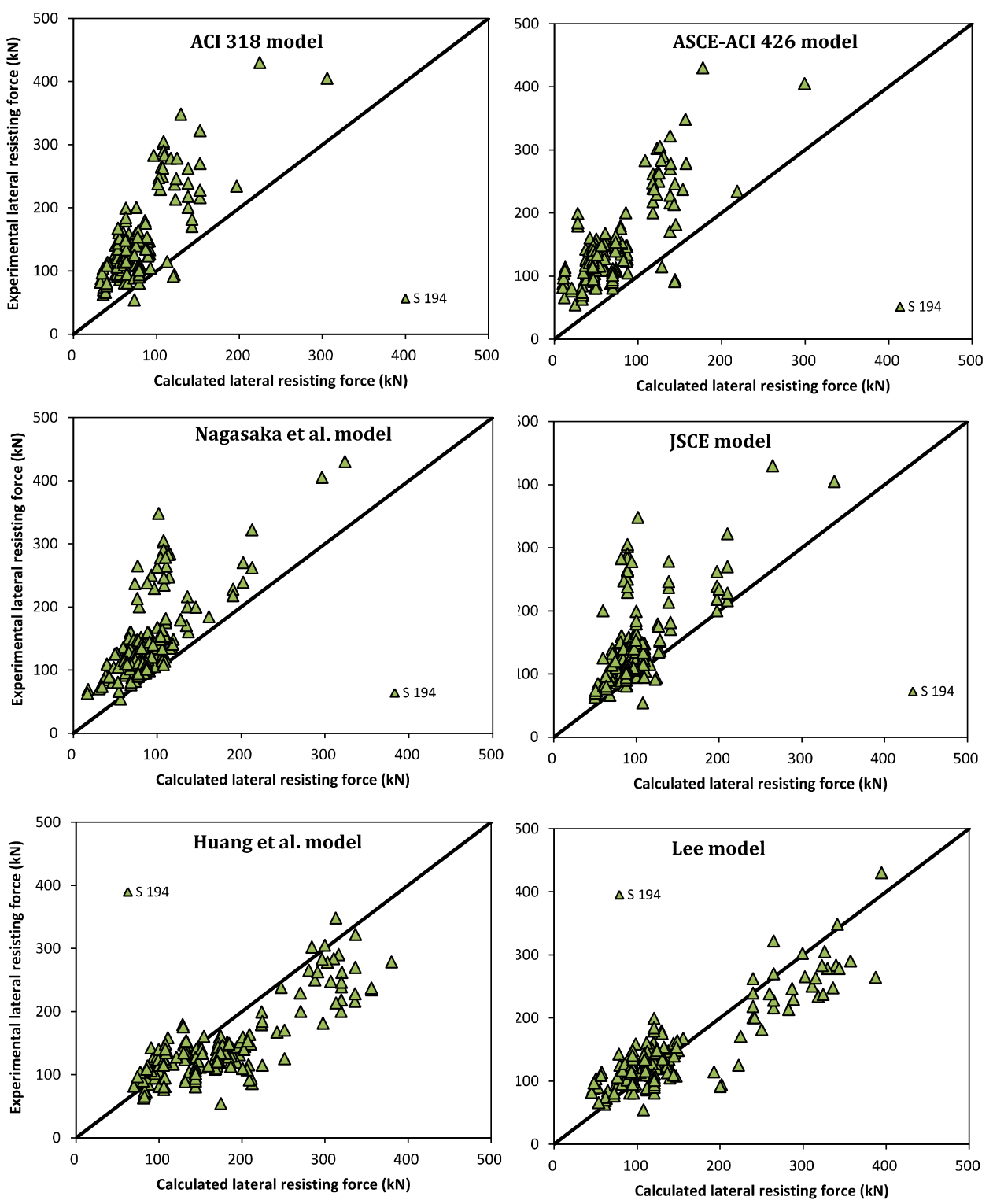

Fig.7 Comparison of various shear strength models in the database
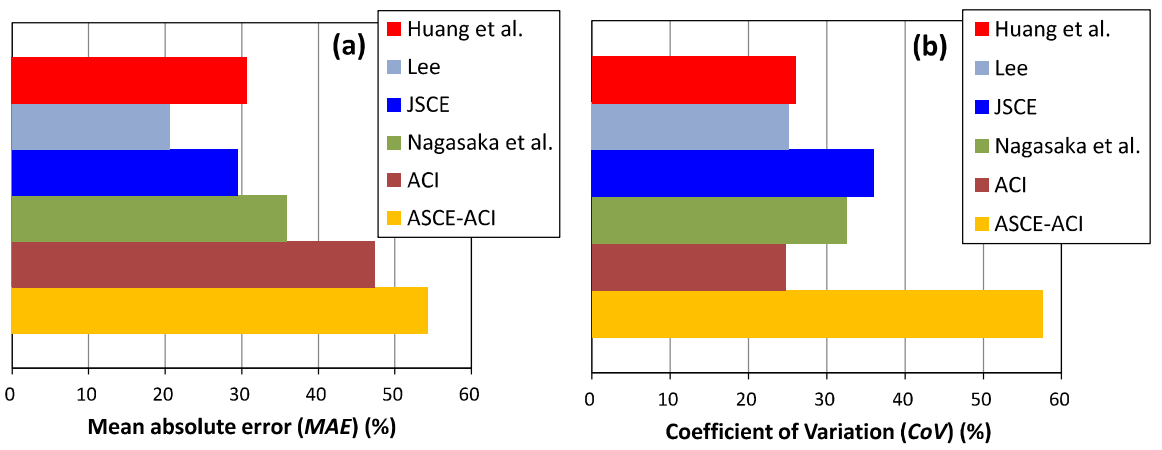

Fig.8 Mean absolute error and coefficient of variation of the predictions 
On the basis of the above descriptions, it can be concluded that all the models from existing design guideline/codes present a high conservativeness, i.e. they have high safety stock when are used to design shear resisting FRC columns under seismic loads. Generally, this can be explained by that they has been developed based on the analyses of normal RC columns without considering the effect of fibre on the deformation and shear transferring. This can be verified by a fact that the conservativeness of JSCE model is improved slightly comparing with other code models for it simply considers the positive effect of fibre on the shear resistance of RC columns. As a code equation, however, it still shows too high design safety stock and discreteness.

Due to the consideration of the fibre effects in columns, on the other hand, Nagasaka et al., Hung et al. and Lee models improve the prediction accuracy of the shear strength of FRC columns more or less, sometimes in mean strength ratio or $\mathrm{CoV}$, sometimes in $R^{2}$, especially Lee model presents a high potential feasibility. This can be contributed on two following things. The first is that original Priestley et al. model [21] used by Lee model clearly explained and considered various shear contributions provided by concrete, arch action from axial load and truss-mechanism of transverse rebars in normal RC members. The second one is that this model modified Priestley et al. model through linearly introducing a shear component provided by fibre based on his test studies and analysing a small database available at that time.

\section{Modification of Priestley et al. model for FRC columns}

In order to understand clearly the shear resistance mechanism of RC column, Priestley et al. model [21] is introduced shortly firstly. As shown in Fig.9 (a), this model considered that the shear strength of RC column is consisted of three main parts, concrete contribution $V_{c}$, truss-mechanism component $V_{s}$ and the contribution from axial load $V_{p}$, as shown in Equation (11). On the basis of the results in the built database, Fig.3 also verifies the axial load level affects significantly shear resisting of RC columns.

$$
V_{n}=0.29 \sqrt{f_{c}^{\prime}} b d+\frac{d-c}{2 a} P+\frac{A_{v} f_{y t} d^{\prime} \cot 30^{\circ}}{S}
$$

According to the above comparative analyses, using the research database as reported above, this study will reconsider the basic assumptions of original Priestley et al. model in FRC columns and the contribution of fibre to the shear strength of FRC columns subjected to seismic loads. The first key enhancement of shear strength caused by the use of fibre is the improvement of crack resisting of the concrete in hinge zone. Subsequently, this directly affects the depth of compressive zone $(c)$ in original Priestley et al. model (see Fig.9). In normal RC columns, Kowalsky and Priestley [29] considered that the typical values of $c / d$ (the compressive depth to overall depth) range from 0.25 to 0.35 . However, as shown in Fig.9, in FRC columns, the added fibres help RC column to resist shear crack development in the main diagonal cracked section, in particular, in narrow cracked section. This will increase the effective compressive depth $c_{R}$ in FRC column. Subsequently, this will improve the arch action in FRC columns caused by axial force, i.e. increase the shear contributions $\left(V_{p}\right)$ in FRC column. It is very important for the FRC columns 
with high axial load ratio. In addition, as shown in Figs.1 (g) and (h), Huang et al. [22] reported that the major shear cracks propagate in the direction of about $37-45^{0}$ in FRC columns with respect to the direction of longitudinal reinforcements, which is similar to the ones reported by other researchers [2, 30-32]. However, it is different with the one proposed by original Priestley et al. model. This difference probably draws a dangerous calculative error for total shear strength of FRC columns. Therefore, in this paper, the calculation of shear resisting capacity of stirrups $V_{s}$ in FRC columns is suggested using the $45^{0}$ truss mechanism adopted by ACI 318 .

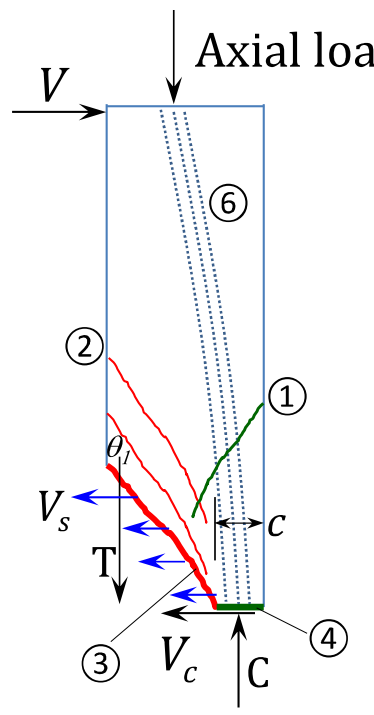

(a) RC columns
(1) Close shear crack;

(2) Non-dominant shear crack;

(3) Dominant shear crack;

(4) Compression zone;

(5) Fibre at crack section;

(6) Arch action;

In FRC columns:

$\theta_{2}>\theta_{1}$

$c_{R}>C$

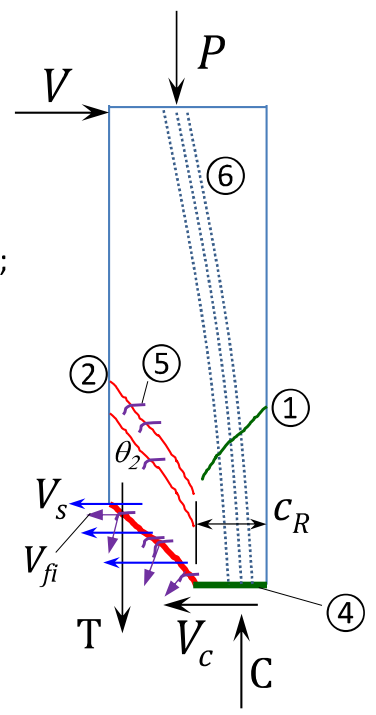

(b) FRC columns

Fig.9 Shear transfer mechanisms consideration in RC/FRC columns

At the same time, as illustrated in Fig.9 (b), the lateral component force obtained from the nondirective tensile actions of fibre at main diagonal cracked section can provide the fourth shear contribution to the total shear resisting of FRC columns, i.e. the one provided by fibre $V_{f}$. For these reasons, to simply present the positive effects of fibre, the compressive depth $c_{R}$ of FRC column under seismic action can be taken as $50 \%$ of overall depth of column. Therefore, the original Priestley et al. model firstly is modified and named as $V_{\text {Priestley. }}$. Subsequently, according to the difference between experimental and calculated shear strengths of this modified model $V_{\text {Priestley, }}$ considering the simplification and uniformity of calculation as well as a fact that the enhancing effect of fibre can be expressed based on the basic concrete compressive $\left(\sqrt{f_{c}^{\prime}} A_{e}\right)$, the relative nominalized difference ratios of all the shear failure specimens are obtained. The relationship between the relative nominalized difference ratios and the volume fraction of fibre can be presented as shown in Fig.10. 


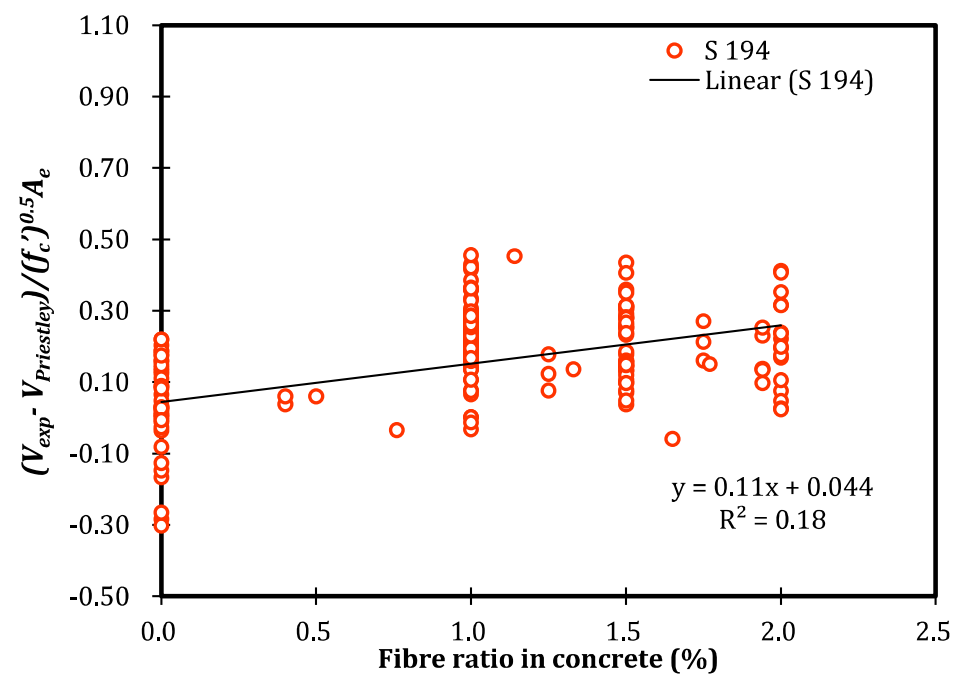

Fig.10 Fiber volume ratio vs. relative difference ratio $\left(V_{\text {exp }}-V_{\text {Priestley }}\right) /\left(f_{c}^{\prime}\right)^{0.5} A_{e}$

According to this figure, the difference ratios increase linearly as the increasing of the fibre in concrete. This means the contribution of shear strength from fibre increases linearly as the using volume fraction of fibre in concrete. Therefore, $V_{f}$ can be simply given by,

$$
V_{f}=\left(11 \rho_{F}+0.044\right) \sqrt{f_{c}^{\prime}} A_{e}
$$

Using the above equation and the reconsiderations in modified Priestley et al. model reported above, the total shear strength of FRC columns under seismic loads can be calculated as,

$$
V_{F R C}=0.29 \sqrt{f_{c}^{\prime}} A_{e}+\frac{d^{\prime}}{4 a} P+\frac{A_{v} f_{y t} d^{\prime}}{S}+\left(0.044+11 \rho_{F}\right) \sqrt{f_{c}^{\prime}} A_{e}
$$

Fig.11 shows the comparison between experimental results from database and the predictions based on the proposed model. Results show that this model can evaluate the experimental results with a very good agreement. Comparing with the results of previous model plotted in Figs.7 and 8, as well as the statistical results listed in Table.5, the strength ratios of the proposed model have a more reasonable mean (1.05) and the smallest values of St.Dev, CoV and MAE, which are 0.18, 16.74\% and 14.47\%, respectively. Additionally, the coefficient of determination $R^{2}$ of the calculated results from proposed model reaches 0.85 , which is most close to 1.0 comparing with other models'. The results indicate that the proposed model presents the highest accuracy, reasonability and reliability. Besides, the comparative results plotted in Fig.12 show the proposed model has not obvious change tendency between strength ratio $\left(V_{\text {exp }} / V_{F R C}\right)$ and some main structural design factors of FRC column. This fact strongly indicates that the proposed model presents high reliability. This means the model will predict well the shear capacity of FRC columns when these structural factors change. 


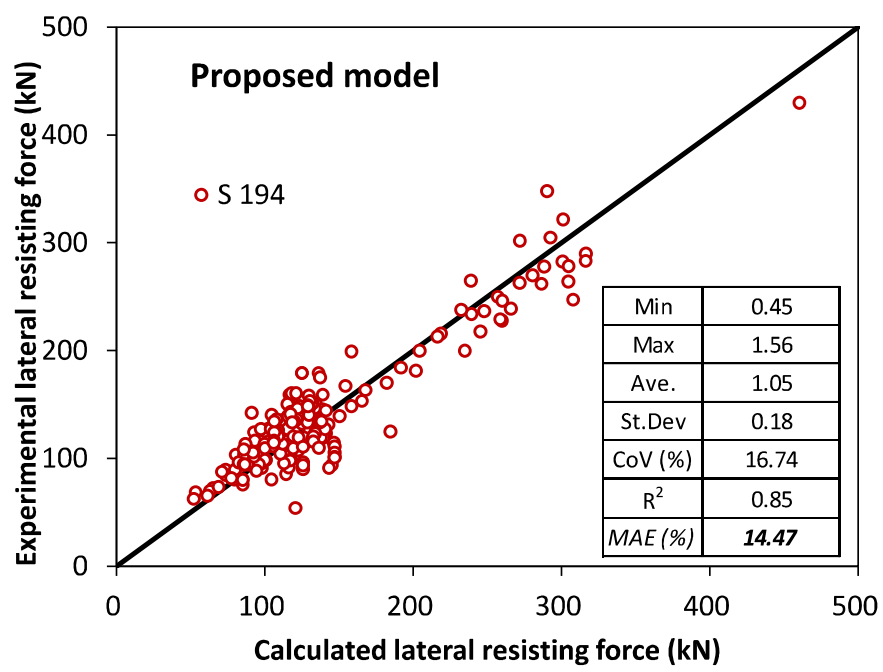

Fig.11 Comparison between experimental results and predictions of the proposed model
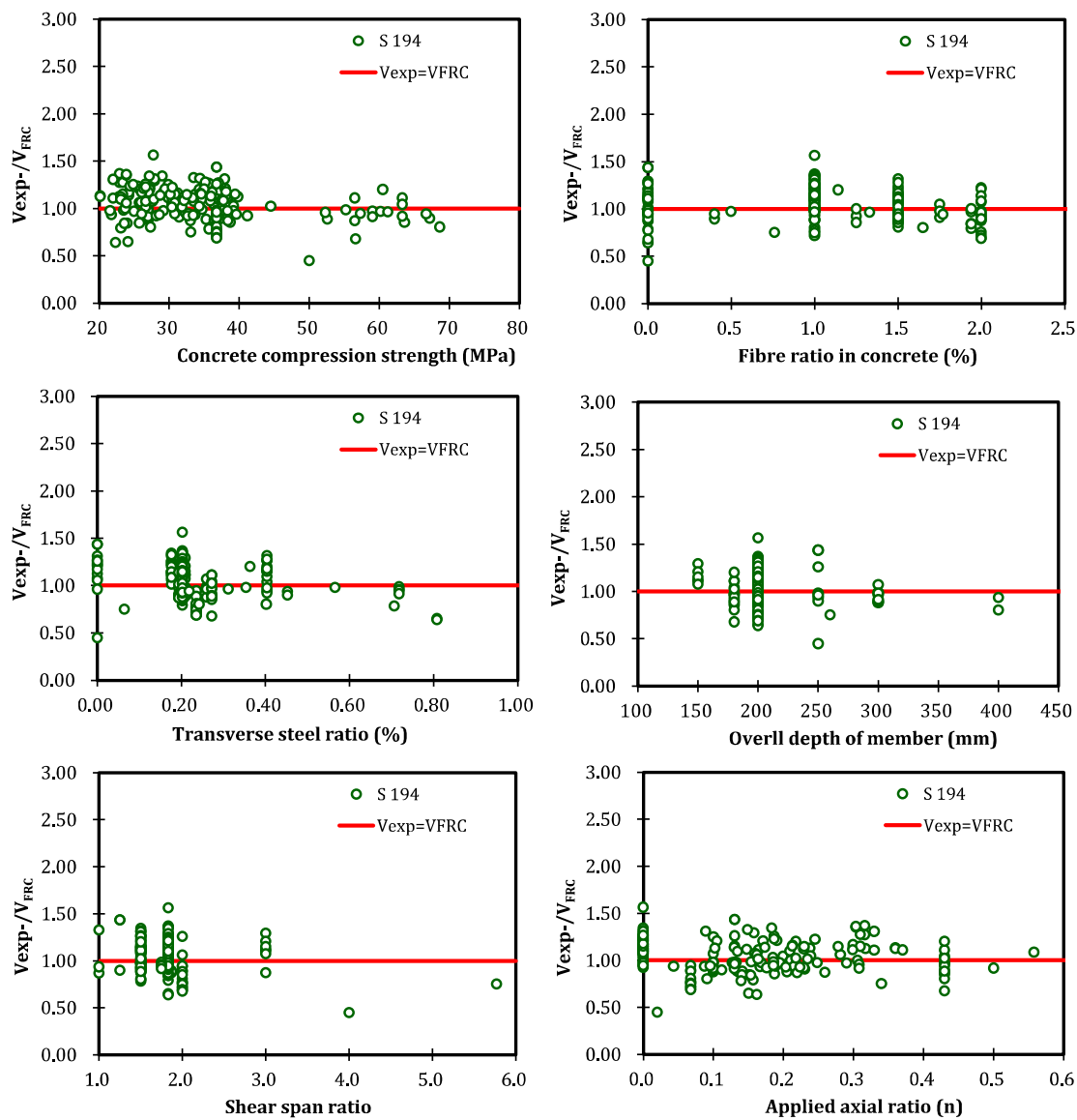

Fig.12 Proposed model compared with experimental results related to main design factors

\subsection{Ultimate flexure capacity-comparison and modification}

Using similar statistical comparative analysis methods as the ones in Section 4.1, the flexural capacity ratio of experimental/calculated moments $\left(M_{\text {exp }} / M_{c a l}\right)$ is used to evaluate the existing flexural models. Fig.13 shows the comparative results and main statistical examination results 
including minimum, maximum, mean, St. Dev, $\mathrm{CoV}, R^{2}$ and $M A E$ values. This figure also includes the predication situation of FRC columns with F-S failure mode as the reference ones. It should be noted that the results of these two models are calculated using fibre reinforced concrete compressive strength $f_{F R C}$ to instead concrete compressive strength $f_{c}^{\prime}$ in original models, because larger evaluation errors are confirmed when $f_{c}{ }^{\prime}$ is applied. The calculation method of $f_{F R C^{\prime}}$ is referred to the study performed by Hung et al. [22], as shown in Table.1. Therefore, the two flexural strength models are renamed as $M_{C E B-F I P}^{\prime}$ and $M^{\prime}{ }_{A I J}$ respectively. Results plotted in Fig.13 show that CEB-FIP model has a better evaluation accuracy comparing with AIJ model. However, the determination ratio $R^{2}$ of the predicted flexural strength ratios from CEB-FIP model just is 0.29 , which means the model still needs to be improved.
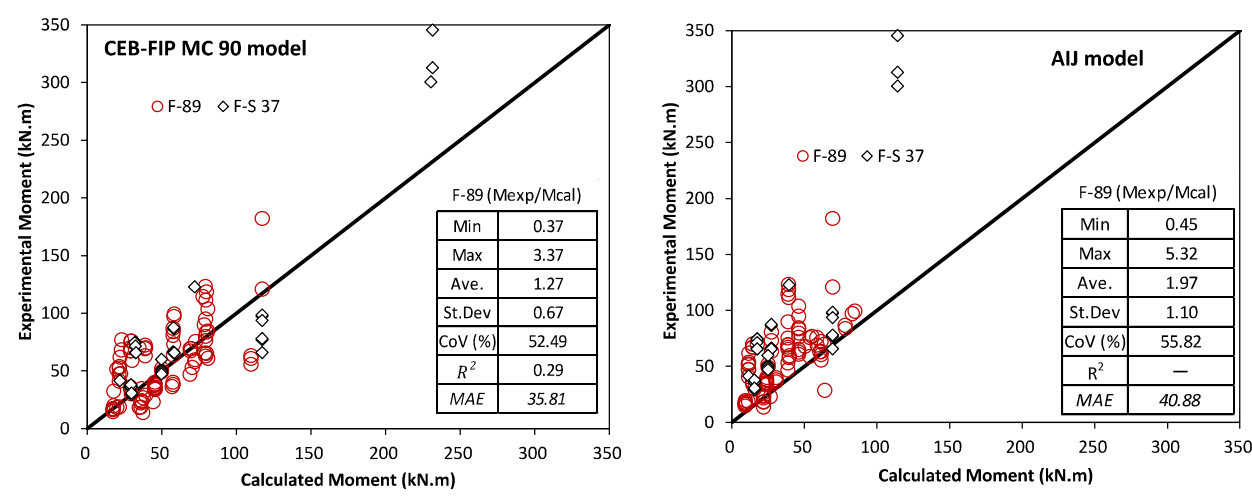

Fig.13 Comparison between existing methods and the experimental results in database

The predication results reported above can be partly contributed on the stress block calculation method of CEB-FIP model ignored the effect of axial load on flexure strength of columns. In 1986, Priestley and Park [33] firstly reported a fact that the enhancing ratio of moment (compared to $\mathrm{ACI}$ ideal moment, i.e. $M_{e x p} / M_{a c i}$ ) is strongly dependent on applied axial load of RC columns. They explained that the reason is a higher axial load means the column has a larger neutral axis depth, which increases concrete contribution and the effect of lateral confinement on concrete. In this paper, similar methods and considerations are used to modify CEB-FIP model, i.e., through investigating and modelling the relationship between the difference ratio of experimental/calculated moments $\left(M_{\text {exp }} / M_{C E B-F I P}^{\prime}\right)$ and applied axial load ratio of FRC columns. As shown in Fig.14 (a), a similar influence relationship is presented in this study. In this figure, because this study uses calculated $f_{F R C}$ ' to modify the moment of columns at first, it is possible that the start point of the curve is less than 1.0 in the figure (when $n=0$ ). As a result, the model firstly is modified taking into account the effect of axial load ratio $(n)$ on the moment of

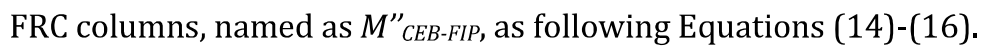

$$
\begin{aligned}
& M_{C E B-F I P}^{\prime \prime}=\kappa_{n} A_{s l} f_{y l}\left(1-0.5 x_{f} / d\right) d \\
& x_{f}=\frac{\omega_{1 f}}{\kappa_{c f}} d=\frac{\rho_{L} f_{y l} /\left(0.95 f_{F R C}^{\prime}\right)}{\left[1-\left(0.95 f_{F R C}^{\prime}\right) / 250\right]} d
\end{aligned}
$$




$$
\kappa_{n}=0.85 e^{1.23 n}
$$

In addition, Harajli [34] reported that shear span ratio $(a / d)$ also significantly affects the ultimate steel stress in calculation section, which strongly influences the ductility and crack development of RC members in hinge zone [35] and the reduction factor of concrete strength due to roughness and size effect [28]. Therefore, using a similar method reported above, referring to the relationship between the difference ratios of the test moment to $M^{\prime \prime}{ }_{C E B-F I P}$ and shear span ratio (see Fig.14 (b)), an affecting factor $\kappa_{s p}$ related to shear span ratio is introduced in Equation (14) to modify the moment calculation of FRC columns, which can be given by,

$$
\begin{aligned}
& M_{F R C}=\kappa_{n} \kappa_{s p} A_{s l} f_{y l}\left(1-0.5 x_{f} / d^{\prime}\right) d^{\prime} \\
& \kappa_{s p}=1.3-0.05(a / d) \geq 0.95
\end{aligned}
$$

where, $\kappa_{s p}$ is taken as greater than 0.95 according to the current database.
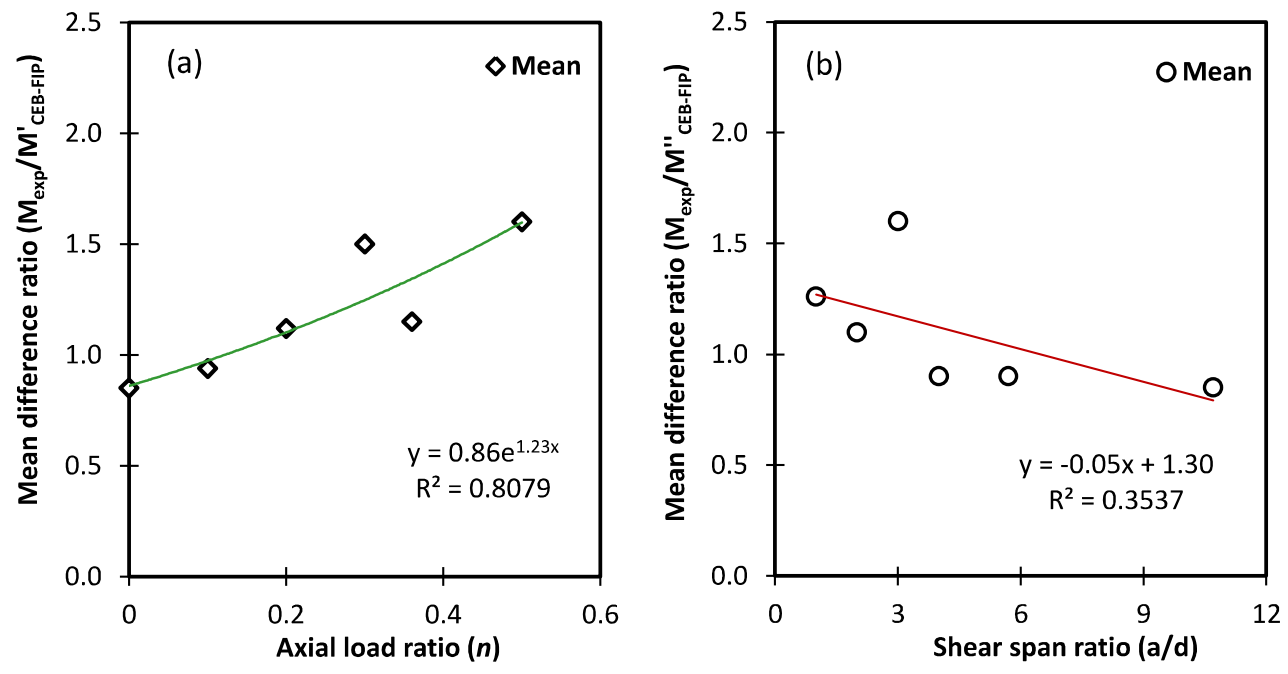

Fig.14 Difference ratio and two considered experimental parameters

The results plotted in Fig.15 indicate that the proposed moment model can evaluate experimental results with a better agreement comparing with above existing models. The values of mean, $R^{2}, M A E$ and $\mathrm{CoV}$ of predicted results are improved that means the model presents more precise and reasonable predication. On the other hand, the prediction of FRC columns with F-S failure mode also exhibits a trend of over-evaluation in a low degree, i.e. the mean value of $M_{\text {exp }} / M_{\text {cal }}$ of FRC columns is less than the one of $\boldsymbol{F}$ failure columns. It is reasonable and normal because the potential increasing shear deformation/damage of these columns reduce the moment capacity of column, like as the predictions of $\boldsymbol{S}$ failure should have a smaller mean moment ratios than the ones of $\boldsymbol{F}$ - $\boldsymbol{S}$ failure columns as well. 


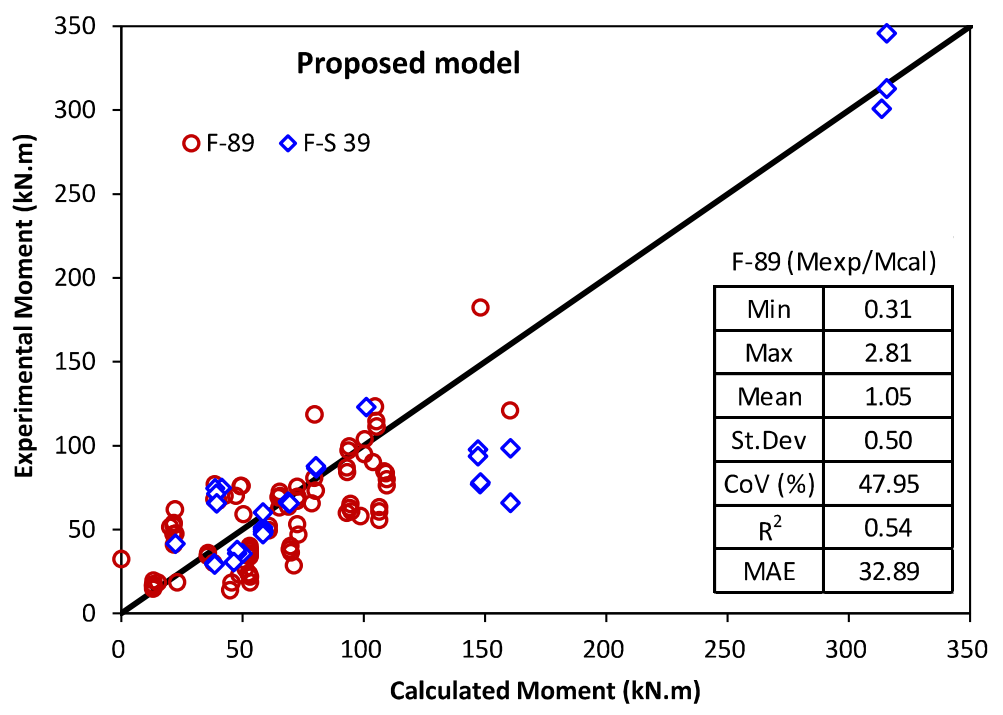

Fig.15 Examination of proposed model with experimental results in database

\subsection{Discussion of failure modes of FRC columns}

As described previously, the prevention of brittle shear failure in RC columns is very important for the RC structures built in seismic prone region. The first author of the paper reported a certification boundary for preventing shear failure in circular RC columns subjected to seismic loads, which considered shear failure can be prevented in circular RC columns when shear span ratio is greater than 2.5 or transverse shear steel ratio exceeds $0.2 \%$ [28]. In this study, for FRC columns, however, as shown in Fig.16 (a), the certification boundary is not correct any more, but is kind of close. Based on the curve in the research [28], the FRC columns maybe will be dangerous when they have a shear span ratio $a / d$ of 2.5 to 3.0. This probably can be explained by the enhancing effect of fibre to flexural resistant is more than the shear resisting part in these middle short FRC columns ( $a / d$ of 2.5 to 3.0). When $a / d$ ratios are less than 3 , the fact that the certification boundary of FRC is very near to Cai et al.'s curve [28] indicates that the use of fibre remedies the reduction of shear resisting in rectangular columns caused by rectilinear transverse rebar. Because using this kind of rebar, the lateral confinement of columns usually is lower comparing the ones provided by spirals in circular RC columns. In other word, the use of fibre improves the lateral confinement of rectangular RC columns which subsequently affects the deformation and ultimate capacity of the columns. According to the research database and analyses above, some characteristics regarding the shear failure of FRC columns can be drawn, as follows,

- The shear span ratios of FRC columns failed as shear failure mode are usually less than 3.0 when used transverse steel ratio is greater than $0.2 \%$;

- Shear failure possibly occur in FRC columns having a small transverse reinforcement ratio. For example, when the ratio is less than the low allow limit of Japanese standard (0.2\%), the 
column fails as shear failure mode, even if the shear span ratio of the column is higher than 3.0 (see Fig. 16 (a));

- The using of fibre could not prevent completely shear failure in FRC columns, as shown in

Fig.16 (b);

Therefore, the point line plotted in Fig.16 (a) can be suggested as a preliminary certification boundary for preventing shear failure in FRC columns subjected to seismic loads. This means the FRC columns under this line will fail as shear failure mode with a high probability. Otherwise, they will fail with a flexure-dominant failure mode. This preliminary judgement will be very helpful to structural designers when they consider FRC in columns in building structures.
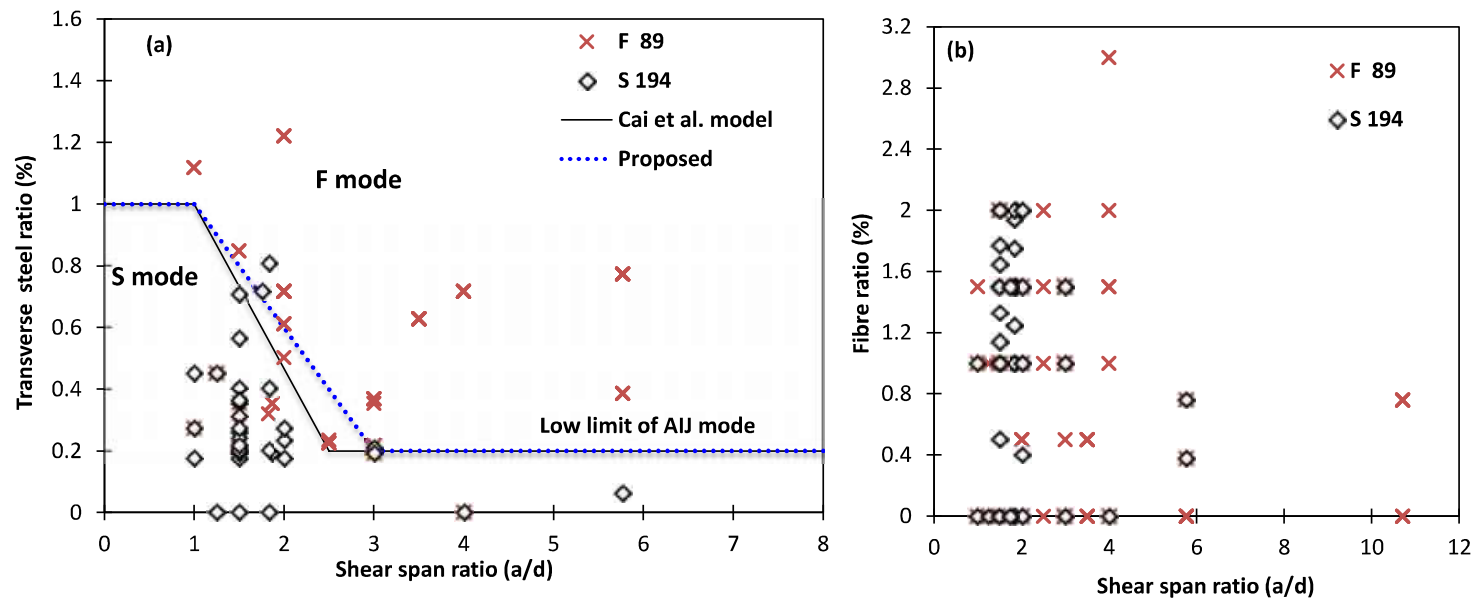

Fig.16 Failure modes of FRC columns and some key parameters

On the other hand, based on the comparative studies and analyses of ultimate capacities of FRC columns, a more detailed and accurate certification method is established. This method is on the basis of the capacity design theory reported by Park and Paulay [36] who imply that RC columns will fail as shear failure mode when their shear resisting capacities are lower than corresponding flexural strength. As a result, to judge accurately the potential failure mode of FRC columns subjected to seismic loads, the key is how to predict accurately the ultimate shear and flexural capacities of FRC columns. Therefore, according to the results reported in Sections 4.1 and 4.2 in this paper, using the proposed ultimate shear and flexural models, the predication of failure modes of FRC columns could be realized.

Fig.17 shows the prediction results of test failure modes of these FRC columns in the database reported above. In this figure, the vertical axis is the strength ratio of experimental maximum lateral force $\left(V_{\max , ~ e x p}\right)$ to calculated flexural strength $\left(V_{f l, c a l}\right)$, which represents the prediction accuracy of flexural strength of FRC columns failed as $\boldsymbol{F}$ failure mode. Similarly, the horizontal axis (calculated shear/flexural strength, $V_{s h, c a l} / V_{f l}$, cal) means the predicted failure mode of FRC columns. The columns will be judged as $F$ failure or $F$-S failure modes if the ratio of $V_{s h, c a l} / V_{f l,}$, cal is greater than 1.0. The results of the Zone $I$ in the figure shows that the failure modes and the shear strengths of these $\boldsymbol{S}$ failure FRC columns both can be evaluated well using these two 
proposed shear models. In Zone $\boldsymbol{I I}$, the prediction results of $\boldsymbol{F} / \boldsymbol{F}-\boldsymbol{S}$ failure modes show $88 \%$ of flexure-dominant failure columns are predicted as $\boldsymbol{F}$ failure mode. Together with the preliminary judgement curve plotted above in Fig.16 (a), the detailed method to assess the potential failure mode of FRC columns is acceptable. At the same time, the results above Zone II indicate that although the proposed moment model made an good improvement comparing with existing two models in FRC columns, the dispersion degree of the predictions of the model still needs to be improved which implies more test investigations are expected.

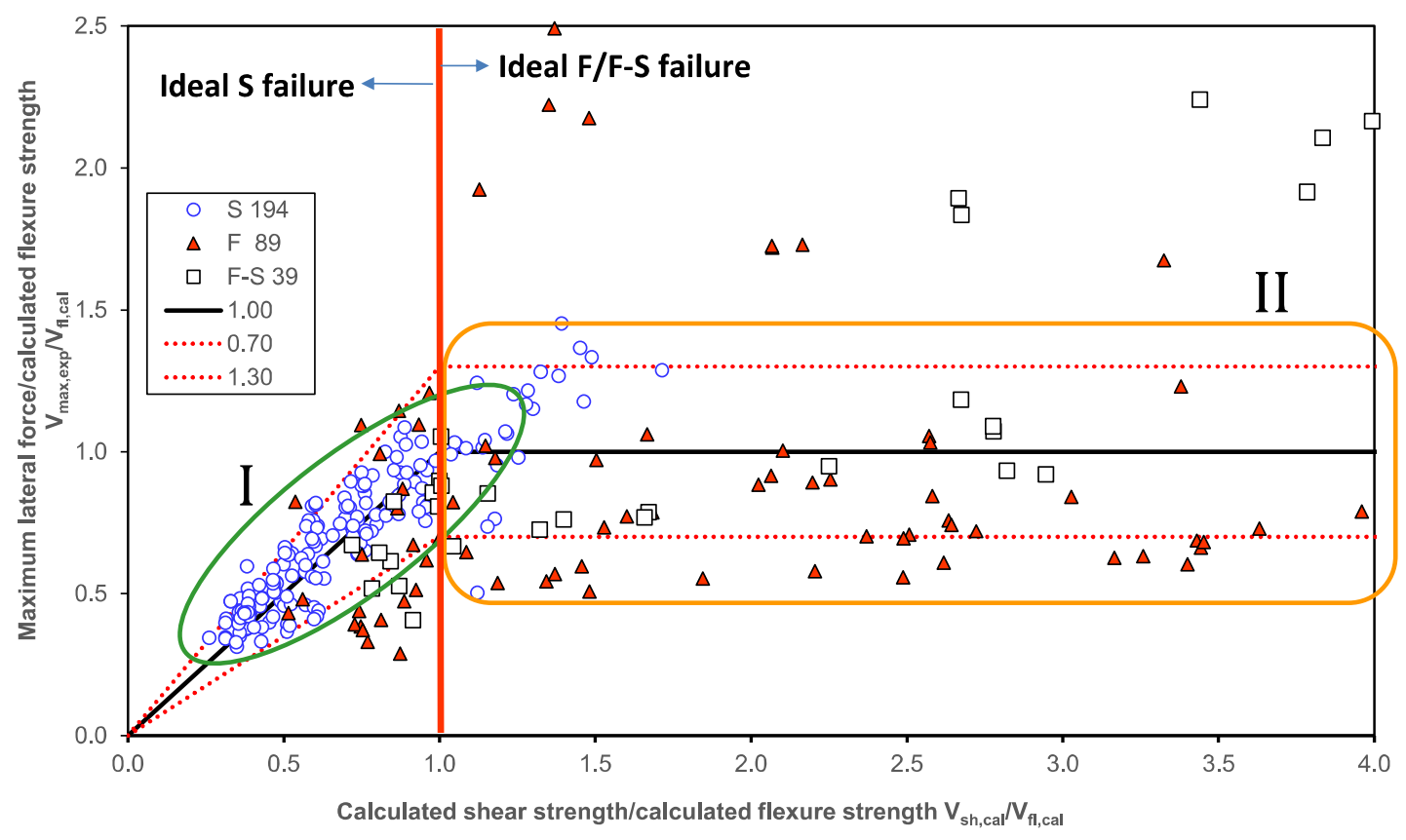

Fig.17 Predicted failure modes vs. experimental results in the database

\section{Summary and conclusions}

In this paper, a seismic research database of FRC columns has been established as a result of a comprehensive literature investigation, which subsequently was used to evaluate the accuracies and conservativeness of existing ultimate capacity design models of FRC/RC columns. At the same time, based on the re-examination of existing models and the reconsideration of the enhance effect of fibre on seismic behaviour of RC columns, two more reasonable strength models to predicate ultimate capacities of FRC columns were proposed. Besides, on the basis of the analyses of the seismic research database and using the two proposed strength models, a complete method to assess the potential failure modes of FRC columns was recommended. The main conclusions derived from this study can be summarized, as follows:

1) The seismic research database built in this paper includes a total of 322 rectangular FRC columns obtained from the literature published mainly in English, Chinese and Japanese from 1979 to present.

2) The accuracies and conservativeness of existing models for calculating shear strength of FRC columns were examined. Results shown that ACSE-ACI, ACI 318 and JSCE shear strength 
models all have a high conservativeness. From the views of total accuracy and discreteness, Lee model presented a relative good accuracy and reliability comparing with other models, however, the results of $\boldsymbol{R}^{2}$ of this model indicates it still needs to be improved.

3) A new proposal for predicting the shear strength of FRC columns was developed based on original Priestley et al. shear model by introducing a shear contribution came from fibre and modifying the calculated depth of compressive zone and the slope degree of main diagonal crack. Comparing with experimental results, this proposed model presented the highest accuracy and reliability than other models.

4) Considering the effect of fibre, axial load and shear span ratio on the moment and deformation capacities of FRC columns, the CEB-FIP moment model was modified for FRC columns subjected to seismic loads. Comparing with the existing models, the proposed model evaluate well the experimental results in the database.

5) This paper provided a detailed method to judge the potential ultimate failure modes of FRC columns and its evaluation feasibility was verified in FRC columns using the database.

\section{References}

1. S.J. Foster, M.M. Attard, Strength and ductility of fiber-reinforced high-strength concrete columns, Journal of Structural Engineering 127 (1) (2001) 28-34.

2. K.E. Caballero-Morrison, J.L. Bonet, J. Navarro-Gregori, P. Serna-Ros, An experimental study of steel fiber-reinforced high-strength concrete slender columns under cyclic loading, Engineering Structures 57 (2013) 565-577.

3. H. Kimura, Y. Ishikawa, A. Kambayashi, H. Takatsu, Seismic Behavior of 200MPa Ultra-High-Strength Steel-Fiber Reinforced Concrete Columns under Varying Axial Load, Journal of advanced concrete technology 5 (2) (2007) 193-200.

4. W.M. Li, J.Y. Xu. Mechanical properties of basalt fiber reinforced geopolymeric concrete under impact loading, Materials Science and Engineering: A 505 (1) (2009) 178-186.

5. S.J. Foster, On behavior of high-strength concrete columns: cover spalling, steel fibers, and ductility, ACI Structural Journal 98 (4) (2001) 583-589.

6. G. Campione, M. Fossetti, M. Papia, Behavior of fiber-reinforced concrete columns under axially and eccentrically compressive loads, ACI Structural Journal 107 (03) (2010) 272-281.

7. H. Aoude, W.D. Cook, D. Mitchell, Behavior of columns constructed with fibers and self-consolidating concrete, ACI Structural Journal 106(3) (2009) 349-357.

8. P. Paultre, R. Eid, Y. Langlois, Y. Lévesque, Behavior of Steel Fiber-Reinforced High-Strength Concrete Columns under Uniaxial Compression, Journal of Structural Engineering -ASCE 136 (10) (2010) 1225-1235.

9. P.H. Bischoff, Tension stiffening and cracking of steel fiber-reinforced concrete, Journal of Materials in Civil Engineering 15 (2) (2003), 174-182.

10. T. Ji, Z.Z. Qian, Effects of steel fiber concrete and width of flat beams on seismic behavior of flat beam-column joint. China Civil Engineering Journal 33 (3) (2000) 42-47.[In Chinese] 
11. American Concrete Institute (ACI 318), Building code requirements for structural concrete (ACI 318-08) and commentary, American Concrete Institute, Detroit Mich, 2008.

12. European Committee for Standardization, Eurocode 8: design of structures for earthquake resistance-Part 1: General rules, seismic actions and rules for buildings, EN 1998-1 (2004). 2004.

13. K.E. Caballero-Morrison, J.L. Bonet, J. Navarro-Gregori, P. Serna-Ros, Behaviour of steel fibre reinforced normal strength concrete slender columns under cyclic loading, Engineering Structures 39 (2012) 162-175.

14. American Concrete Institute, Manual of concrete practice, ACI. 2002.

15. Y.P. Sun, K. Sakino, T. Yoshioka, Flexural behavior of high strength RC columns confined by rectilinear reinforcement, Journal of Structural Construction Engineering 486 (1996) 95-106.

16. MC90, CEB-FIP, Design of Concrete Structures, CEB-FIP Model Code 1990, fib Fédération internationale du béton, 1993.

17. Architectural Institute of Japan, Design guidelines for earthquake resistant reinforced concrete buildings based on inelastic displacement concept, Architectural Institute of Japan, Tokyo, 1997.

18. ASCE/ACI Joint Task Committee 426, Shear Strength of Reinforced Concrete Members, Journal of Structural Engineering-ASCE 99 (6) (1973) 1091-1187.

19. Japan Society of Civil Engineers, Design guidelines of steel fiber reinforced concrete pillar member (draft), Japan Society of Civil Engineers, 1999. [In Japanese]

20. H.H. Lee, Shear strength and behavior of steel fiber reinforced concrete columns under seismic loading, Engineering structures 29 (7) (2007) 1253-1262.

21. M.J. Nigel Priestley, R. Verma, Y. Xiao, Seismic shear strength of reinforced concrete columns, Journal of structural engineering 120 (8) (1994) 2310-2329.

22. L. Huang, L.H. Xu, Y. Chi, H.R. Xu, Experimental investigation on the seismic performance of steel-polypropylene hybrid fiber reinforced concrete columns, Construction and Building Materials 87 (2015) 16-27.

23. T. Nagasaka, T. Yanase, Study on Shearing Characteristics of Steel Fiber Reinforced Concrete Structural Members : Part 1 and Part 2, in Annual Meeting Architectural Institute of Japan, 1986. [In Japanese]

24. AIJ, Standard for Structural Calculation of Reinforced Concrete Structures, Architectural Institute of Japan (AIJ), pp.136-153, 1999.

25. J.R. Tang, C.B. Hu, K.J. Yang, Y.C. Yan, Seismic behavior and shear strength of framed joint using steel-fiber reinforced concrete, Journal of Structural Engineering-ASCE 118 (2) (1992) 341-358.

26. M. Berry, M. Parrish, M. Eberhard, PEER Structural Performance Database, 2004, http://nisee.berkeley.edu/spd/ 
27. E. Makitani, K. Machida, H. Gunjima, I. Hagiwara, Dynamic Effect on Shearing Behavior of Steel Fiber Reinforced Concrete Columns, Proceeding of Japan Concrete Institute (1985) 361-364. [In Japanese]

28. G.C. Cai, Y.P. Sun, T. Takeuchi, J.W. Zhang, Proposal of a complete seismic shear strength model for circular concrete columns, Engineering Structures 100 (2015) 399-409.

29. M.J. Kowalsky, M.J.N. Priestley, Improved analytical model for shear strength of circular reinforced concrete columns in seismic regions, ACI Structural Journal 97 (3) (2000) 388-396.

30. Y. Tanaka, Y. Kaneko, H. Yashiro, Experimental Studies on the Shear Failure Properties of Steel Fiber Reinforced Concrete Short Columns Loaded by Show Reversals, Proceeding of Japan Concrete Institute (1984) 517-520. [In Japanese]

31. M. Hara, T. Nagasaka, M. Sugiyama, Mixing effect of steel fibers in the Reinforced Concrete Columns Subjected to repeated horizontal load, Part 1, Research report at Kanto Branch of AIJ (1982) 157-160. [In Japanese]

32. X.W. Liang, L. Kang, J.L. Che, M.K. Deng, Experiments and analysis of seismic behavior of columns with fiber-reinforced concrete in bottom region, Engineering mechanics 32 (9) (2013) 243-250.[In Chinese]

33. M.J.N. Priestley, R. Park, Strength and ductility of concrete bridge columns under seismic loading, ACI Structural Journal, 84 (1) (1987) 61-76.

34. M.H. Harajli, Effect of span-depth ratio on the ultimate steel stress in unbonded prestressed concrete members, ACI Structural Journal, 87(3) (1990) 305-312.

35. T.Y. Lim, P. Paramasivam, S.L. Lee, Shear and moment capacity of reinforced steel-fibre-concrete beams, Magazine of Concrete Research 39 (140) (1987) 148-160.

36. R. Park, T. Paulay, Reinforced concrete structures, John Wiley \& Sons, New York, 1975. 


\section{Appendix A: References for the database}

1. Y. Zhang, H. Wei, W. Yuan, Test for seismic behavior of bridge piers with local steel fiber reinforced concrete, Journal of vibration and shock 31(2) (2012) 102-107.[in Chinese]

2. M. Hara, T. Nagasaka, T. Yanase, Mixing effect of steel fibers in the Reinforced Concrete Columns Subjected to repeated horizontal load, Part 2, Research report at Kanto Branch of AIJ (1983) 157-160. [In Japanese]

3. F.L. Li, C.K. Huang, S.C. Wen, J.W. OU, Ductility of steel fiber reinforced high strength concrete columns under cyclic loading, Engineering mechanics 22(6) (2005) 159-164.[in Chinese]

4. K.E. Caballero-Morrison, J.L. Bonet, J. Navarro-Gregori, P. Serna-Ros, An experimental study of steel fiber-reinforced high-strength concrete slender columns under cyclic loading, Engineering Structures 57 (2013) 565-577.

5. K.E. Caballero-Morrison, J.L. Bonet, J. Navarro-Gregori, J.R. Martí-Vargas, Behaviour of steel-fibre-reinforced normal-strength concrete slender columns under cyclic loading, Engineering Structures, 39 (2012) 162-175.

6. Y. Kurihashi, F. Taguchi, N. Kishi, H. Mikami, An experimental study on ductility of RC pier mixed with PVA short-fiber, Japan Civil Engineering Research Institute for Cold Region, Monthly report (651) (2007) 10-17. [In Japanese]

7. N. Okamoto, S. Matsubara, Study on shearing characteristics of steel fiber reinforced concrete structure members: part 12. ductility after flexural yielding, Annual Meeting Architectural Institute of Japan-Structures II (1985) 315-316. [In Japanese]

8. M. Hara, T. Nagasaka, N. Takashi, Experimental study on the effect of reinforcing steel fibers in RC long column, Annual Meeting Architectural Institute of Japan, Structures II (1979) 1299-1300. [In Japanese]

9. M. Hara, T. Nagasaka, S. Makoto, Mixing effect of steel fibers in the Reinforced Concrete Columns Subjected to repeated horizontal load, Part 1, Research report at Kanto Branch of AIJ (1982) 157-160. [In Japanese]

10. M. Sakai, N. Nagamura, Improving toughness of reinforced concrete columns by steel fiber. Proceeding of Japan Concrete Institute (1979) 309-312. [In Japanese]

11. E. Makitani, T. Fujiwara, Experimental study on the method of reinforcement steel fiber reinforced concrete, Research report at Kanto Branch of AIJ (1981) 237-240. [In Japanese]

12. Y. Itabashi, J. Kabeyazawa, Y. Suenaga, M. Sakai, Strength and Ductility of Fiber Reinforced Concrete Column, Proceeding of Japan Concrete Institute (5) (1983) 321-324.[In Japanese] 
13. Y. Tanaka, Y. Kaneko, H. Yashiro, S. Fukushima, Experimental Studies on the Shear Failure Properties of Steel Fiber Reinforced Concrete Short Columns Loaded by Show Reversals, Proceeding of Japan Concrete Institute (1984) 517-520. [In Japanese]

14. E. Makitani, K. Machida, K. Korishima, I. Ogihara, Shear behavior and dynamic effect of steel fiber reinforced concrete columns, Proceeding of Japan Concrete Institute (1985) 361-4. [In Japanese].

15. L. Huang, L.H. Xu, Y. Chi, H.R. Xu, Experimental investigation on the seismic performance of steel-polypropylene hybrid fiber reinforced concrete columns, Construction and Building Materials 87 (2015) 16-27.

16. H. Kimura, H. Takatsu, Y. Ishikawa, H. Takeda, Experimental study of high-strength SFRC made of using steel fiber, Proceedings of Japan Concrete Institute 25(2) (2003) 235-240. [In Japanese]

17. X.W. Liang, L. Kang, J.L. Che, Mingke Deng, Experiments and analysis of seismic behavior of columns with fiber-reinforced concrete in bottom region, Engineering mechanics, 32 (9) (2013) 243-250.[In Chinese]

18. H.H. Lee, Shear strength and behavior of steel fiber reinforced concrete columns under seismic loading, Engineering structures 29(7) (2007) 1253-1262.

19. T. Nagasaka, K. Yanagisawa, Study on shearing characteristics of steel fiber reinforced concrete structure members: Part 1, Annual Meeting Architectural Institute of Japan. Structures II (1986) 1867-1868. [In Japanese]

20. E. Makitani, K. Machida, M. Yanagisawa, I. Ogihara, Study on shearing characteristics of steel fiber reinforced concrete structure members: Part 4, Annual Meeting Architectural Institute of Japan. Structures II, 1873-1874.[In Japanese]

21. T. Okamoto, T. Yamada, M. Kiyoshiko, Study on shearing characteristics of steel fiber reinforced concrete structure members: Part 5, Annual Meeting Architectural Institute of Japan. Structures II (1984) 2081-2082.[In Japanese]

22. T. Nagasaka, K. Yanagisawa, K. Yanase, Study on shearing characteristics of steel fiber reinforced concrete structure members: Part 9, Annual Meeting Architectural Institute of Japan. Structures II (1985) 309-310.[In Japanese]

23. T. Nagasaka, K. Yanagisawa, K. Yanase, Study on shearing characteristics of steel fiber reinforced concrete structure members: Part 10, Annual Meeting Architectural Institute of Japan. Structures II (1985) 311-312.[In Japanese]

24. T. Nagasaka et al., Study on shearing characteristics of steel fiber reinforced concrete structure members: Part 11. Annual Meeting Architectural Institute of Japan. Structures II (1985) 315-316.[In Japanese]

25. T. Nagasaka, K. Yanagisawa, T. Ando, Study on shearing characteristics of steel fiber reinforced concrete structure members: part 21, Annual Meeting Architectural Institute of Japan, Structures II (1986) 543-544. [In Japanese] 
26. T. Nagasaka, K. Yanagisawa, Takashi Ando, Experimental Study on Shear Strength of steel fiber reinforced concrete mixing and pillar. Proceeding of Japan Concrete Institute (1984) 521-524. [In Japanese]

Appendix B - seismic research database of FRC columns 